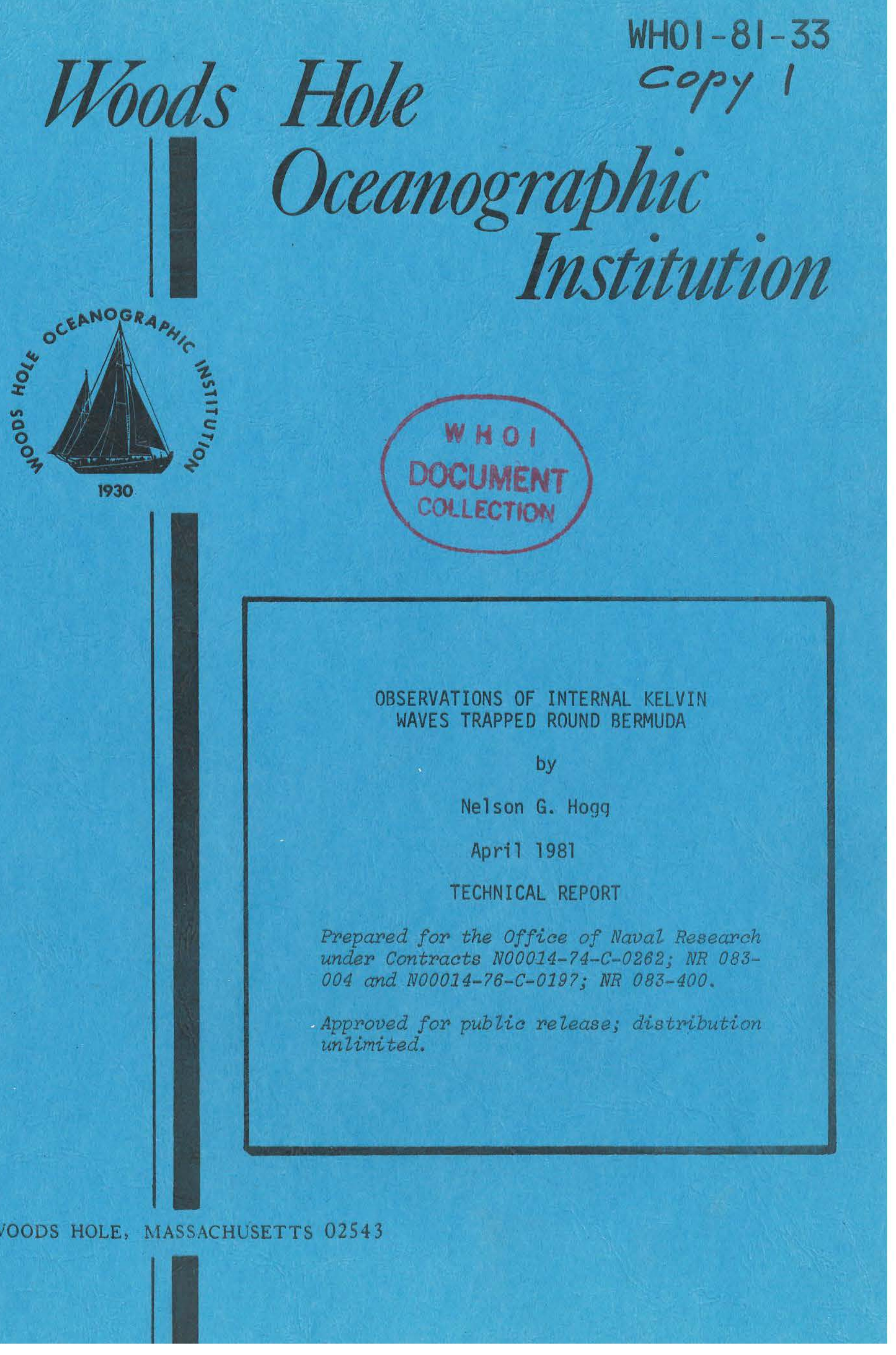


WHOI $-81-33$

OBSERVATIONS OF INTERNAL KELVIN

WAVES TRAPPED ROUND BERMUDA

by

Nelson G. Hogg

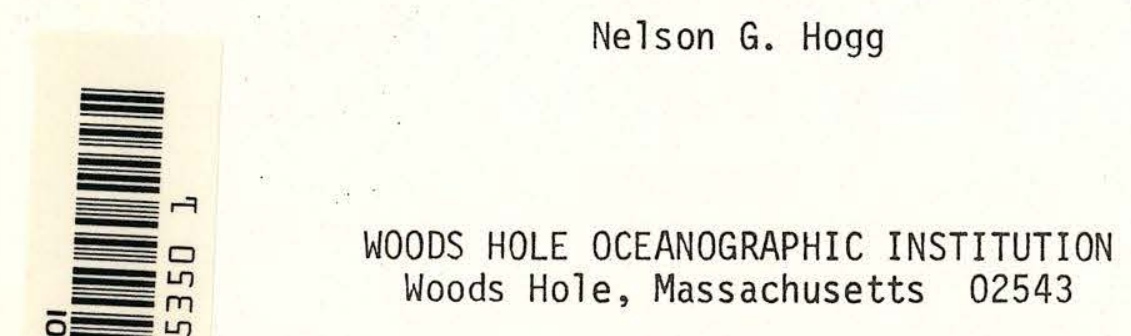

Apri1 1981

TECHNICAL REPORT

Prepared for the Office of Naval Research under Contracts N00014-74-C-0262; NR 083-004 and N00014-76-C-0197; NR 083400.

Reproduction in whole or in part is permitted for any purpose of the United States Government. In citing this report in a bibliography, the reference given should be to: Journal of Physical Oceanogrophy 10(9): 1353-1376 (September $1980 \%$.

Approved for public release; distribution unlimited.

Approved for Distribution: Valentine Worthington, Chairman Department of Physical Oceanography 


\title{
Observations of Internal Kelvin Waves Trapped Round Bermuda
}

\author{
NELSON G. HogG \\ Woods Hole Oceanographic Institution, Woods Hole, MA 02543
}

(Manuscript received 5 July 1978, in final form 9 April 1980)

\begin{abstract}
Observations of the vertical and horizontal structure of motions near Bermuda have been made with two long-term moored arrays, one relatively far from and the other close to the island. Although not coincident in time, both arrays see horizontally coherent motions at 11 frequency bands ranging in period from 405 to $9.8 \mathrm{~h}$. Only a peak at $26.1 \mathrm{~h}$ appears to be significant in the autospectra and, on several grounds, this is identified with the fundamental island-trapped mode (vertically and azimuthally).

Additional resonant subinertial periods are at roughly 45,54 and $90 \mathrm{~h}$ and these are vertical modes 2,3 or 4 and azimuthal modes 1 or 2 propagating clockwise. The superinertial modes have less internal consistency but appear to have higher order vertical and azimuthal structures and both senses of azimuthal phase propagation.

The subinertial vertical structure is modal and can be rationalized with baroclinic wave dynamics on a sloping bottom by defining an effective bottom depth as some reasonable average over the offshore decay scale.

The subinertial motions are coherent with the surface wind stress and the phase between this forcing and the response changes by $180^{\circ}$ across the trapped wave frequency bands consistent with a resonant system. The $Q$ of the 26.1 h peak is at least 20 implying that dissipation has only a slight influence on the dynamics.
\end{abstract}

\section{Introduction}

The fact that wave energy can be trapped along coastlines has been known for many years and there is now a well-developed body of literature concerning both the theory and observations. Theoretical studies range from the simplest homogeneous flatbottomed models to those which include coastline irregularities, offshore depth variations, stratification and the earth's rotation. Three classes of trapped waves have been identified: 1) the classical Kelvin wave, a gravity wave forced to propagate with the shoreline to its right (in the Northern Hemisphere); 2) edge waves with frequencies above the inertial which can travel in either direction and exist only when there are offshore depth variations; and 3) quasi-geostrophic topographic waves with frequencies below the inertial which, like Kelvin waves, always propagate with the coast to their right. Reid (1958) has given a particularly illuminating study of the latter two classes in a homogeneous fluid of constant bottom slope, while there have been many elaborations attempting to include more realistic bottom slopes and stratification effects (e.g., Allen, 1975; Mysak, 1967, 1968; Wang and Mooers, 1976; Huthnance, 1975, 1978; Fuller and Mysak, 1977; Ou, 1979).

Along infinite straight coasts the dispersion relation for trapped waves is continuous so that the most convincing evidence for their existence comes from studies of phase propagation as observed by simultaneous measurements at several locations such as those reported by Cutchin and Smith (1973) and Wang and Mooers (1977) for surface height data.

When the shoreline is closed either, for example, as in a lake or an island, waves with an integral number of wavelengths round the perimeter reinforce themselves; a resonant system which leads to a discrete spectrum exists as opposed to the continuous one in the straight coastline case. In the island geometry, only motions with frequencies below inertial are perfectly trapped while those above inertial radiate energy to infinity (LonguetHiggins, 1967, 1969), although Longuet-Higgins (1967) has shown that these motions can be effectively trapped by suitable offshore depth variations which refract outward propagating waves and guide them around the island.

Spectral peaks and nonzero longshore phases in surface height observations have been reported by Longuet-Higgins (1967) and Summerfield (1969) in a superinertial band for Macquarie Island and by Miyata and Groves (1968) and Longuet-Higgins (1971) for Oahu in a subinertial band. Wunsch (1972) has observed spectral peaks at a range of sub- and superinertial frequencies in time series of temperature from $550 \mathrm{~m}$ depth off Bermuda and identified 
TABle 1. Vital statistics of the two Bermuda moored arrays. $P=$ pressure, $U=$ east component, $V=$ north component, $T=$ temperature.

\begin{tabular}{|c|c|c|c|c|c|c|}
\hline $\begin{array}{c}\text { Record } \\
\text { no. }\end{array}$ & Location & $\begin{array}{l}\text { Bottom } \\
\text { depth (m) }\end{array}$ & $\begin{array}{l}\text { Instrument } \\
\text { depth }(m)\end{array}$ & Date set & $\begin{array}{c}\text { Duration } \\
\text { (days) }\end{array}$ & Comments \\
\hline \multicolumn{7}{|c|}{ Far-field array } \\
\hline $\begin{array}{l}5531 \\
5534 \\
5535\end{array}$ & $\begin{array}{l}31^{\circ} 46.9^{\prime} \mathrm{N} \\
64^{\circ} 26.2^{\prime} \mathrm{W}\end{array}$ & 4353 & $\begin{array}{r}306 \\
1005 \\
1505\end{array}$ & 29 Apr 75 & $\begin{array}{l}272 \\
272 \\
272\end{array}$ & $\begin{array}{l}T, U, V \\
T, U, V \\
T \text { only }\end{array}$ \\
\hline $\begin{array}{l}5541 \\
5544 \\
5545\end{array}$ & $\begin{array}{l}32^{\circ} 21.5^{\prime} \mathrm{W} \\
65^{\circ} 27.0^{\prime} \mathrm{W}\end{array}$ & 4774 & $\begin{array}{r}314 \\
1013 \\
1513\end{array}$ & $29 \mathrm{Apr} 75$ & $\begin{array}{l}271 \\
271 \\
271\end{array}$ & $\begin{array}{l}T, U, V \\
T, U, V \\
T \text { only }\end{array}$ \\
\hline $\begin{array}{l}5551 \\
5555 \\
5556\end{array}$ & $\begin{array}{l}32^{\circ} 59.0^{\prime} \mathrm{N} \\
64^{\circ} 23.8^{\prime} \mathrm{W}\end{array}$ & 4527 & $\begin{array}{r}316 \\
516 \\
1516\end{array}$ & 30 Apr 75 & $\begin{array}{l}270 \\
270 \\
270\end{array}$ & $\begin{array}{l}T, U, V \\
T, U, V \\
T \text { only }\end{array}$ \\
\hline \multicolumn{7}{|c|}{ Near-field array } \\
\hline $\begin{array}{l}6331 \\
6332 \\
6333\end{array}$ & $\begin{array}{l}32^{\circ} 33.8^{\prime} \mathrm{N} \\
64^{\circ} 44.7^{\prime} \mathrm{W}\end{array}$ & 1795 & $\begin{array}{r}795 \\
1095 \\
1395\end{array}$ & 15 Nov 77 & $\begin{array}{l}384 \\
384 \\
347\end{array}$ & $\begin{array}{l}P, T, \text { no speeds } \\
T, U, V \\
T, U, V \text {, recorder } \\
\quad \text { malfunction } \\
T, U, V\end{array}$ \\
\hline $\begin{array}{l}6341 \\
6342 \\
6343\end{array}$ & $\begin{array}{l}32^{\circ} 32.3^{\prime} \mathrm{N} \\
64^{\circ} 44.1^{\prime} \mathrm{W}\end{array}$ & 1096 & $\begin{array}{l}396 \\
696 \\
996\end{array}$ & 16 Nov 77 & $\begin{array}{l}395 \\
395 \\
395\end{array}$ & $\begin{array}{l}P, T \\
T, U, V \\
T, U, V\end{array}$ \\
\hline $\begin{array}{l}6351 \\
6352 \\
6353\end{array}$ & $\begin{array}{l}32^{\circ} 22.4^{\prime} \mathrm{N} \\
65^{\circ} 00.9^{\prime} \mathrm{W}\end{array}$ & 1117 & $\begin{array}{r}417 \\
717 \\
1017\end{array}$ & 17 Nov 77 & $\begin{array}{l}394 \\
394 \\
394\end{array}$ & $\begin{array}{l}P, T \\
T, U, V \\
T, \text { no speeds }\end{array}$ \\
\hline
\end{tabular}

them with internal Kelvin waves but, in this case, no longshore phase information was available.

Herein we report on moored observations made near Bermuda in and below the main thermocline from two long-term current meter arrays. Observational methods and the treatment of the acquired data are described in the next section. The observations are presented in Section 3 and provide evidence for the existence of trapped internal waves at four subinertial and several superinertial frequency bands.

The theory of baroclinic Kelvin wave trapping around cylindrical islands is briefly reviewed in Section 4. It is shown that motions at the four subinertial frequencies are consistent with Kelvin waves if one takes the bottom depth to be some average depth over the waves' offshore decay scale. On this basis the first four vertical modes are suggested and in Section 5 this identification is shown to be in rough agreement with observations of the vertical structure.

The question of generating mechanism is discussed in Section 6 and conclusions are given in Section 7.

\section{Methods \\ a. Current meter arrays}

Two arrays have been deployed near Bermuda in recent years on a scale large enough to observe trapped wave propagation around the island. Table 1 summarizes the vital statistics of these moorings and Fig. 1 shows their positions. The earlier array, moorings 553-555 (henceforth referred to as the farfield array), was deployed for nine months from

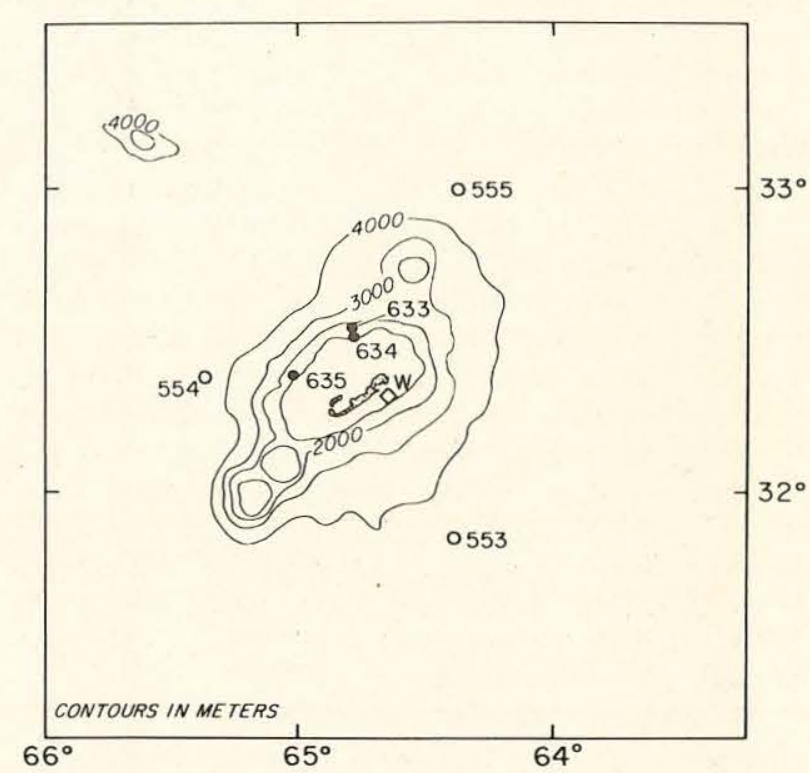

Fig. 1. Locations of far- and near-field arrays and point measurements analyzed by Wunsch (1972) near Bermuda (553$555,633-635$ and $\mathrm{W}$, respectively). 

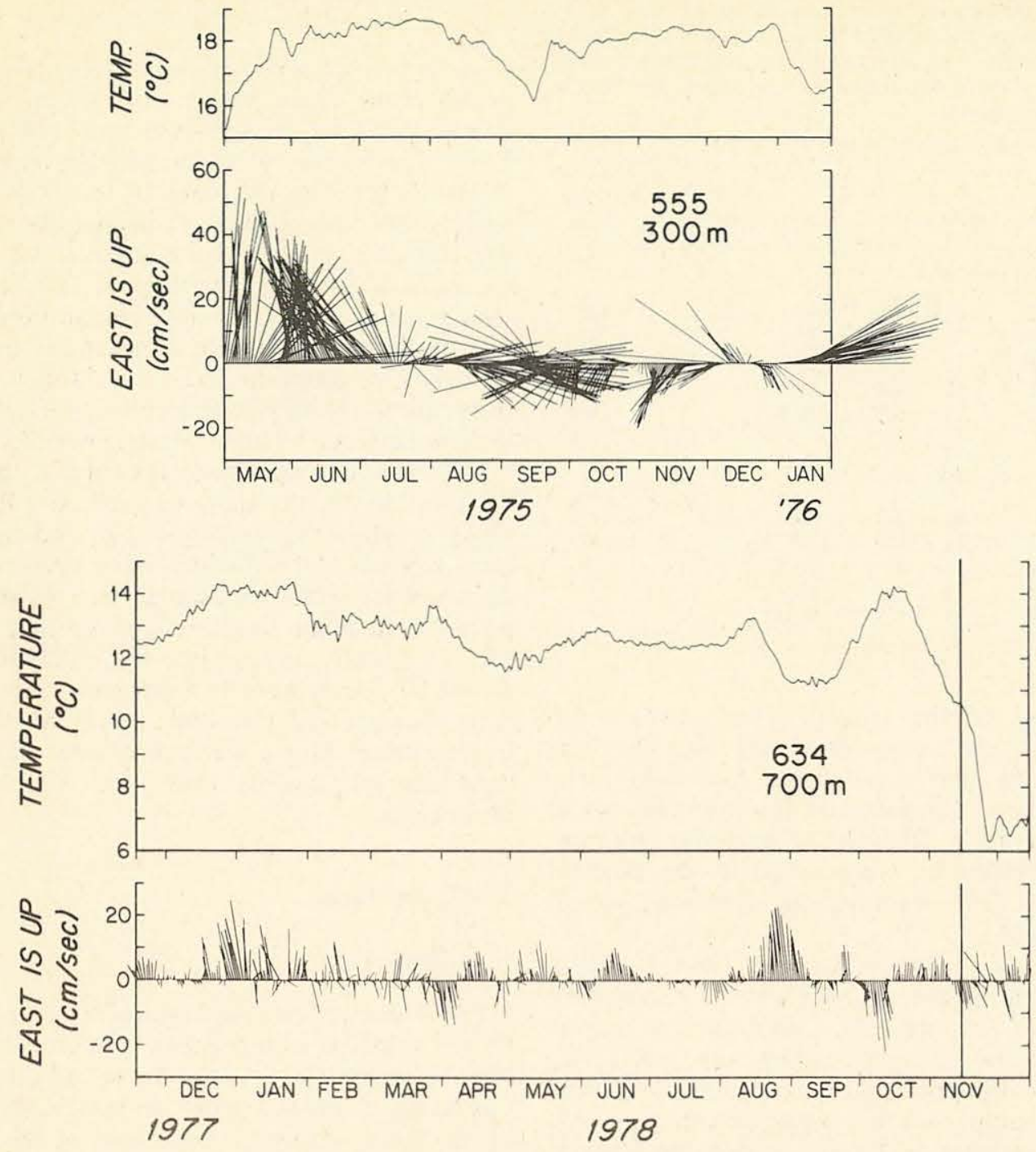

FIG. 2. Low-passed time series of temperature and horizontal velocity on moorings $555(300 \mathrm{~m})$ and $634(700 \mathrm{~m})$. For statistical analysis purposes the latter series were truncated at the time shown in mid-November 1978 just prior to the arrival of a large-amplitude Gulf Stream Ring.

April 1975 through January 1976 to monitor the lowfrequency flow field during an intensive shipboard program investigating mixing processes near the island. An unexpected result of this array was the identification of spatially coherent motions at certain discrete frequencies. Subsequently, in November 1977 moorings 633-635 (henceforth, the near-field array) were deployed closer in to the island in order to investigate the dynamics of these motions. This was recovered in December 1978 after nearly 14 months exposure.

There were instrument problems on both arrays. In addition to the 300,1000 and $1500 \mathrm{~m}$ depth levels on the far-field array noted in Table 1, instruments were also placed at 500 and $700 \mathrm{~m}$ but record lengths varied from a few months to full term in such a way that it was not possible to compute meaningful statistics either around the ar- ray or between mooring pairs. At $1500 \mathrm{~m}$ corrosion eventually stopped all the rotors leaving only temperature as useful information. On the near-field array two rotors were damaged and the cassette recorder jammed in the instrument at $1400 \mathrm{~m}$ on 633 after about 10 months.

\section{b. Time series methods}

Typical time series of current and temperature are shown in Fig. 2 for $300 \mathrm{~m}$ on 555 and $700 \mathrm{~m}$ on 634. For illustration these have been lowpassed by a Gaussian-shaped filter with a half-power point at $24 \mathrm{~h}$ (Schmitz, 1974). In the earlier record two or three low-frequency events occur which are believed to be the passage of Gulf Stream Rings (Hogg et al., 1978). During the second experiment there is a single large-amplitude disturbance near 
TABLE 2. Coordinates of the moorings in two elliptical models of the island bathymetry. Model A is a subjective fit to the $1000 \mathrm{~m}$ isobath and model B is intended to represent the $2000 \mathrm{~m}$ isobath. The last column gives the angles through which the velocity vector has been rotated.

\begin{tabular}{|c|c|c|c|c|c|c|}
\hline Mooring & $\begin{array}{c}x \\
(\mathrm{~km})\end{array}$ & $\begin{array}{c}y \\
(\mathrm{~km})\end{array}$ & $u$ & $\begin{array}{c}v \\
(\operatorname{deg})\end{array}$ & $\underset{(\mathrm{km})}{\rho}$ & $\begin{array}{l}\text { Coordinate } \\
\text { rotation } \\
\text { (deg) }\end{array}$ \\
\hline \multicolumn{7}{|c|}{ Model A, $1000 \mathrm{~m}$ isobath } \\
\hline $\begin{array}{l}553 \\
554 \\
555 \\
634 \\
635\end{array}$ & $\begin{array}{r}-8 \\
-35 \\
68 \\
12 \\
-12\end{array}$ & $\begin{array}{r}-61 \\
32 \\
25 \\
12 \\
13\end{array}$ & $\begin{array}{l}1.9 \\
1.6 \\
2.0 \\
0.7 \\
0.7\end{array}$ & $\begin{array}{r}-97 \\
135 \\
20.9 \\
59.9 \\
119.3\end{array}$ & 19.5 & $\begin{array}{r}-140 \\
65 \\
-20 \\
0 \\
50^{\circ}\end{array}$ \\
\hline \multicolumn{7}{|c|}{ Model B, $2000 \mathrm{~m}$ isobath } \\
\hline $\begin{array}{l}553 \\
554 \\
555 \\
634 \\
635\end{array}$ & $\begin{array}{r}4 \\
-23 \\
80 \\
24 \\
0\end{array}$ & $\begin{array}{r}-61 \\
32 \\
25 \\
12 \\
13\end{array}$ & $\begin{array}{l}1.3 \\
0.9 \\
1.5 \\
0.4 \\
0.3\end{array}$ & $\begin{array}{r}-86.8 \\
116.7 \\
19.1 \\
52.7 \\
90.0\end{array}$ & 36.7 & $\begin{array}{r}-140 \\
65 \\
-20\end{array}$ \\
\hline
\end{tabular}

the very end of the record. These events undoubtedly introduce nonstationarity into the time series and, for that reason, the near-field array series have been truncated at the point shown in Fig. 2b-leaving a full year of available information. No adjustments were made to the far-field array as the little information remaining would have large gaps.

From this point the time series were low-pass filtered with a simple average over $3 \mathrm{~h}$ and then subsampled at $3 \mathrm{~h}$ intervals. Common time origins were established for each array and the series broken into overlapped pieces, typically 270 points long. From each piece the means were removed, the series prewhitened, Fourier transformed, piece averaged, recolored and hanned. [See Hunt (1977) for details of the WHOI algorithm.] Some experimenting was done with the parameters available before deciding that the above prescription was the best compromise between the resolution requirements and statistical stability.

\section{c. Geometrical, angular separations}

Resonance occurs at certain discrete frequencies when an integral number of wavelengths circumscribe the island. For a circular island phase differences between any two azimuthally separated measuring points will be quantized in integral multiples of that appropriate to the fundamental mode. Bermuda is more elliptical in shape than circular but we might expect azimuthal phases to be quantized at roughly integral multiples of the fundamental. We can define an elliptic system with an angular coordinate $u$ measured relative to the major axis and a radial coordinate $v$ according to

$$
x=\rho \cosh u \cos v, \quad y=\rho \sinh u \sin v,
$$

$x$ and $y$ being Cartesian coordinates relative to the center of the ellipse with $x$ along the major axis and $\rho$ is a scale factor (see Morse and Feshbach, 1953). Even this geometry is not entirely appropriate to Bermuda for different isobaths have different ellipticities. We have chosen to consider two extremes the $1000 \mathrm{~m}$ isobath surrounding just the island and the $2000 \mathrm{~m}$ isobath containing the two banks to the southwest as well. Angular separations between moorings and parameters computed from these two models are given in Table 2. Model B derived from the more elliptic geometry gives closer separations between all moorings except 553 and 554 .

It is also convenient to investigate the velocity observations in the more natural curvilinear coordinate system, tangent and perpendicular to the local isobath. All velocities have been rotated and decomposed into longshore and offshore components. Rotation angles are given in Table 2 and are not exactly appropriate for either model A or $\mathrm{B}$ but lie somewhere in between. Errors in these rotation angles will introduce some inaccuracy to the intermooring phase determinations but this will generally be smaller than that due to random processes.

\section{Observations}

\section{a. Autospectra}

Fig. 3 displays autospectra of longshore and offshore velocity components and temperature at $1000 \mathrm{~m}$ depth from both the far and near fields. The velocity field is more or less isotropic in the far field but strongly anisotropic in the near field with longshore currents dominating offshore by more than an order of magnitude at the lowest frequencies and only approaching isotropy at the highest frequencies. Except for the inertial and semidiurnal tidal frequencies there are no significant peaks in the far field, while in the near field there exists a prominent peak in the vicinity of $26 \mathrm{~h}$ and evidence for another in the 50-100 h range.

The distribution of energy at the inertial frequency in the far field $(22-23 \mathrm{~h})$ is typical of the open ocean with a strong peak in the velocity field but not in the temperature implying quasi-horizontal motions. Close to the island the velocity peak is much subdued in the longshore component, completely absent in the offshore component, but quite prominent in temperature. It appears that the island slope severely constrains the horizontal, circular motions and the adjustment forces water up and down slope giving rise to a temperature signal. A complete discussion of the inertial peak is beyond the slope of the present investigation. 

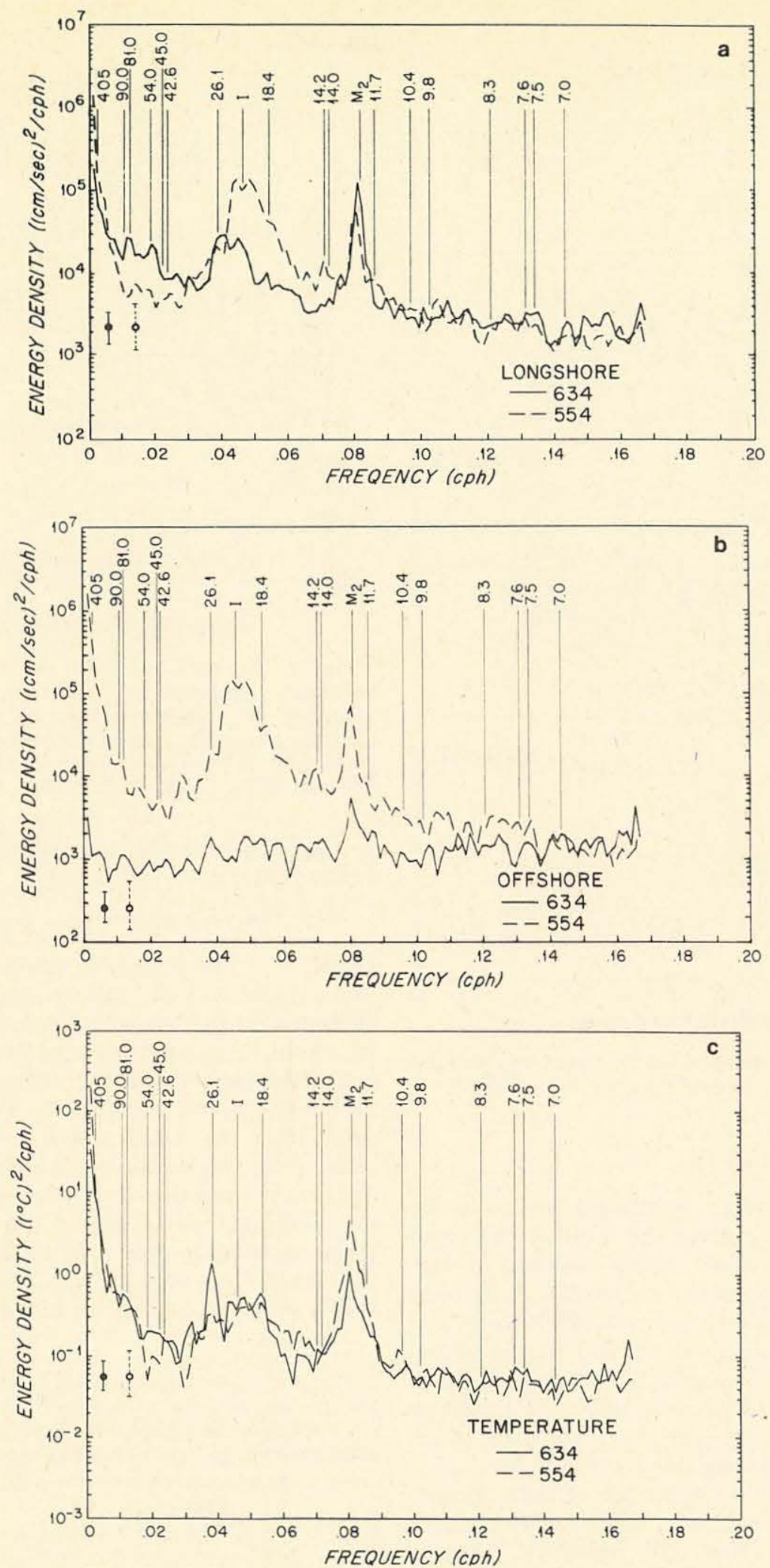

FIG. 3. A comparison of autospectra of (a) longshore and (b) offshore velocity components, and (c) temperature between far- and near-field arrays at $1000 \mathrm{~m}$ depth. Periods indicated are judged significantly at the $95 \%$ level in the analysis of cross-spectral information below ( $I=$ inertial frequency). 


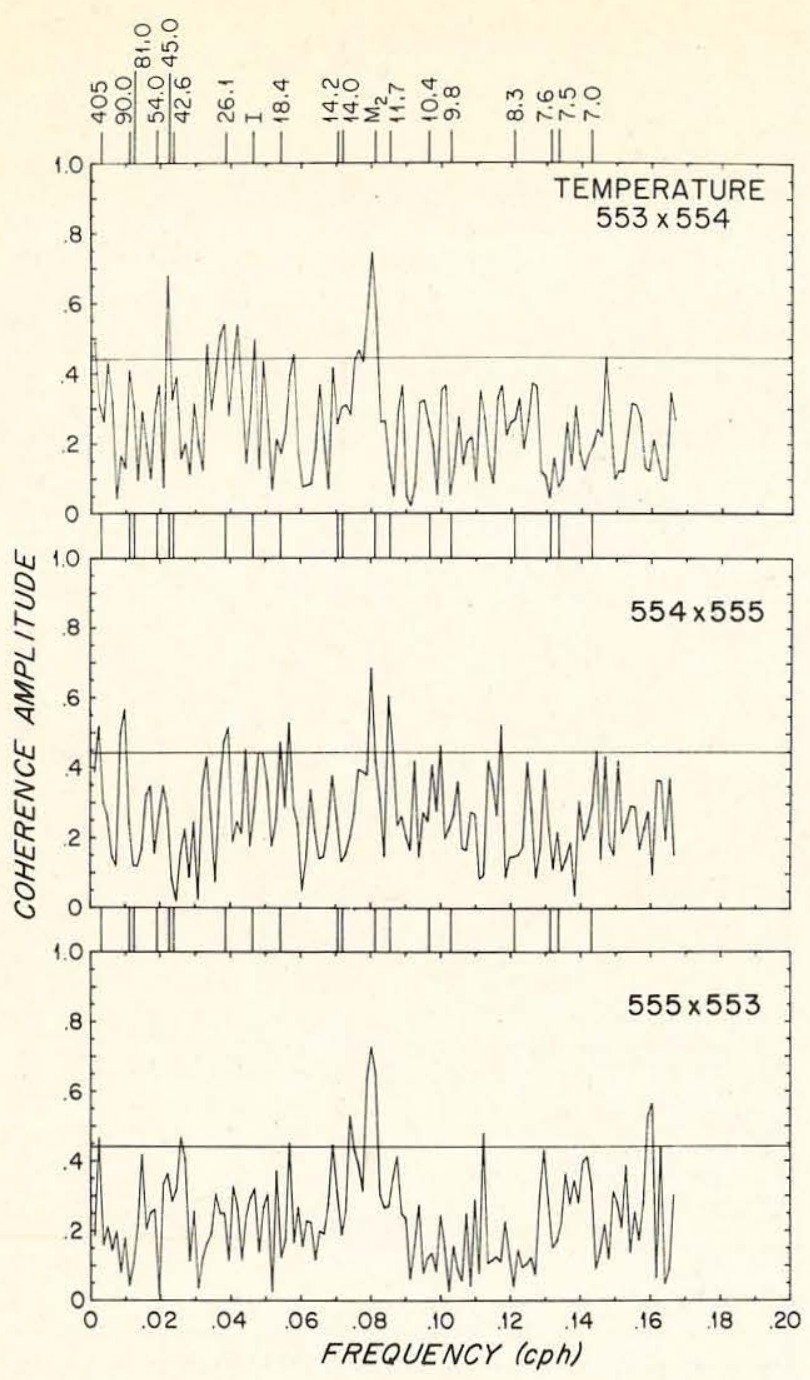

FIG. 4. Coherence amplitudes versus frequency for the three possible pairs in the far-field array at $1000 \mathrm{~m}$ depth.

\section{b. Azimuthal cross spectra}

Although there are no significant peaks in the far field autospectra outside the inertial and semidiurnal tidal bands there are a number of frequency bands in which the azimuthal coherence amplitudes are significantly nonzero ( $95 \%$ level). For example, in Fig. 4 we show the coherence amplitudes for temperature around the far-field array at $1000 \mathrm{~m}$ depth. At the $95 \%$ level there are a number of periods of significant coherence some of which are common to more than one mooring pair.

Of course, we would expect $5 \%$ of these peaks, on the average, to be derived from purely random variations, given a Gaussian process. What is needed is a measure of whether or not there is significant coherent energy around the array. Associated with each coherence value $C_{i j}\left(\omega_{k}\right)$, say, is a cumulative probability that the observed amplitude

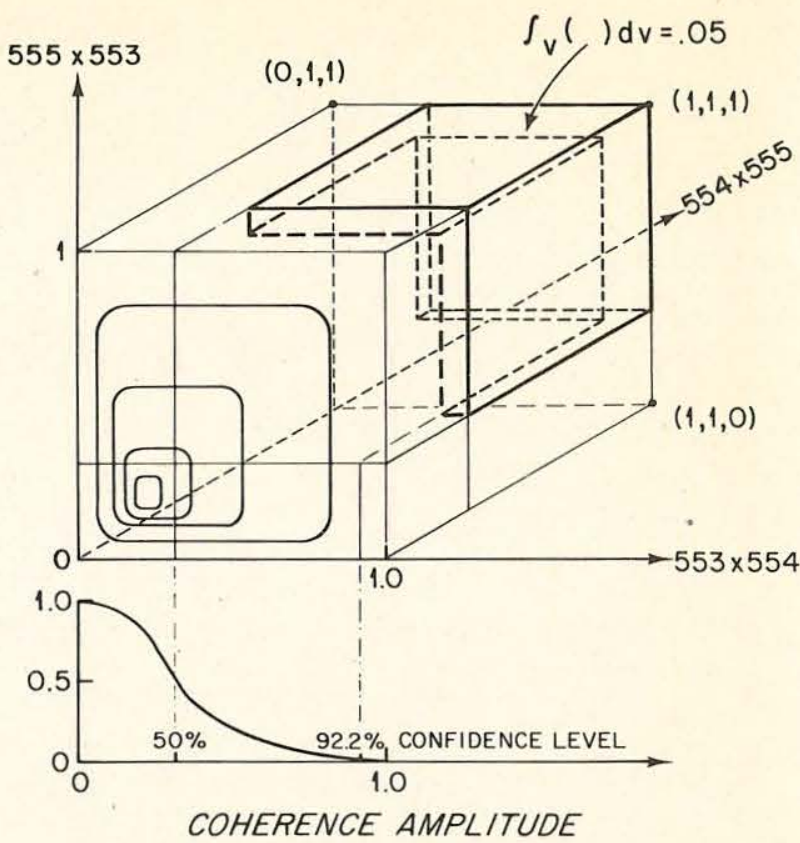

Fig. 5. Schematic view of the three-dimensional joint probability distribution for coherence amplitude at a single depth and for a single variable. The $95 \%$ level is approximated by having the mass of the octant equal to 0.05 . This is satisfied by all three individual confidence levels being above $50 \%$ and at least one above $92.2 \%$.

is a result of random variations which is given by Julian (1975) as

$$
P_{i j}\left(C_{i j} ; \omega_{k}\right)=\left[1-C_{i j}{ }^{2}\left(\omega_{k}\right)\right]^{n-1},
$$

where $n$ is the effective number of pieces used to compute the cross-spectrum $(0.95 \times$ the number of pieces for the hanning window). Treating each of the three pairs as an independent realization (the null hypothesis)-then a three-dimensional joint probability distribution can be formed by taking the product of the three individual probabilities. We wish to find those events which have significantly nonzero coherence at all three pairs. Requiring the individual coherences to be all above the $95 \%$ level would be unduly restrictive. Instead, we have defined the test of significance to be satisfied by all points in the octant given by the individual cumu-

TABLE 3. Upper bounds on the joint cumulative probability distributions. When any of the three-dimensional joint cumulative probabilities out of the seven possible fall below the values indicated there is judged to be significantly nonzero joint coherence.

$$
99 \% \quad 95 \%
$$

$n \quad 1-\alpha=\left(0.014 / C_{n}{ }^{7}\right)^{1 / n} \times 100 \quad 1-\alpha=\left(0.078 / C_{n}{ }^{7}\right)^{1 / n} \times 100$

\begin{tabular}{lcc}
\hline 1 & 0.19 & 1.08 \\
2 & 2.5 & 6.0 \\
3 & 7.3 & 13.0 \\
4 & 16.0 & 26.2 \\
\hline
\end{tabular}


lative probabilities each being $<0.50$ and the integral over the volume of probability density space shown in Fig. 5 being $1-\alpha$. For $\alpha$ close to unity the joint probability density curves will be almost cubical and the volume integral over the inside of the cubical octant can be approximated by

$$
\left[\int_{C_{50 \%}}^{C_{\alpha}} p_{i j}\left(C_{i j}\right) d C_{i j}\right]^{3}=1 / 8-(1-\alpha),
$$

where $C_{\alpha}$ is the coherence amplitude corresponding to the $\alpha$ confidence level. Significant joint coherence results when all three estimates events are above the $50 \%$ confidence level and at least one has large enough amplitude to satisfy (2). ${ }^{1}$

An example computation of the joint probability is shown in Fig. 6 for temperature at 300 and $1000 \mathrm{~m}$ in the far-field array with all those values not falling in the appropriate octant adjusted to one minus their computed probability. There are a number of jointly significant events and one would like a further objective way of combining the information from the different variables and depths to make an overall statement of significance.

Recognizing that the dynamic processes will favor different variables at different depths we have searched for a way of making such an overall assessment of the seven resulting joint probability distributions at each estimate (two velocities and temperature at 300 and $1000 \mathrm{~m}$ and temperature at $1500 \mathrm{~m})$. Treating them as independent, an upper bound on the probability that any $n$ of the seven cumulative distributions will be above the $\alpha$ confidence level is given by

$$
P=\frac{7 !}{(7-n) ! n !}(1-\alpha)^{n} .
$$

For $P=0.01(99 \%)$ and $0.05(95 \%), 1-\alpha$ for each $n$ is given in Table 3 . Those estimates are selected which have one or more of the seven cumulative joint distributions falling in the proper octant of three-dimensional probability space and have joint probabilities less than the critical ones indicated in Table 3. At the $99 \%$ level if only one of the seven is in the proper octant then its individual confidence level must be at least $99.8 \%$ whereas if there are two then each must be at least $96.5 \%$ and so on.

At the $95 \%$ significance level there are some 10 frequency bands (excluding the $12.4 \mathrm{~h}$ tide and its harmonic at $6.2 \mathrm{~h}$ ) judged significant and these are listed in Table 4. Four of these $(405,45.0,26.1$ and $11.7 \mathrm{~h}$ ) are also significant at the $99 \%$ level.

\footnotetext{
${ }^{1}$ The joint $95 \%(99 \%)$ confidence level, so defined, is equivalent to an individual confidence level of $92.2 \%(98.6 \%)$ and the requirement that all three coherence amplitudes be above the $50 \%$ confidence level.
}

Joint cumulative probabilities and octant number ( 7 is the significant octant and 4,5 and 6 indicate one coherence amplitude is below the $50 \%$ level) are also given along with those individual coherence amplitude and phase estimates which are significant at the $95 \%$ confidence level. Phase errors are estimated according to the formula given in Koopmans (1974).

In Table 4 we have included one additional estimate, that centered at $54.0 \mathrm{~h}$, which is close to being significant at the $95 \%$ level and appears more prominently in the near-field array.

A joint cumulative probability distribution has also been computed for the near-field array through considering the azimuthal pairs of temperature coherences at the three common depths on moorings 634 and 635 (top panel, Fig. 6). Here there are broad regions of the frequency domain below the inertial and a number of estimates above which pass the significance test. From inspection of the vertical structure of these motions (to be discussed below) we have found the periods $405,90.0,54.0$, 42.6 and $26.1 \mathrm{~h}$ to be representative of the subinertial motions. The coherence information for these periods and those at superinertial frequencies judged to be statistically significant (excluding the 12.4 tide and its harmonic) are given in Table 5 . It is noteworthy that practically all of these periods are common, or approximately so, to both the nearand far-field arrays. The principal exceptions are the 11.7 and $8.3 \mathrm{~h}$ periods absent in the near-field array and the 7.0, 7.5 and 7.6 h periods absent in the far-field array. None of this last group has individual coherences amplitudes which are significant at the $95 \%$ level, although they do pass the joint $95 \%$ confidence test.

Near-field coherence amplitudes and phases for temperature are shown in Fig. 7 for all the possible azimuthal pairs from moorings 634 and 635 . Note the large number of strongly coherent periods (especially $26.1 \mathrm{~h}$ ) and the positive phases generally measuring between $50^{\circ}$ and $150^{\circ}$ and indicating propagation from 635 to 634 clockwise round the island.

\section{c. Azimuthal mode numbers}

If the periods listed in Tables 4 and 5 are resonant periods of trapped wave motion, then the measured phases should be roughly quantized at integral multiples of the angular separations between the measuring sites given in Table 2. For the two elliptical geometries the expected phases are listed in Table 6 as a function of azimuthal mode number. In Tables 4 and 5 under the columns titled $M$ we give computations of azimuthal mode number consistent with the statistical errors in the phase measurements and Table 6 . There are an 
TABLE 4. Coherent and phase information for the far-field array with estimated azimuthal mode number $(M)$ and computed geometrical angular separations. Where the phase is positive the first mooring lags the second. Also given are the joint cumulative probabilities and the octant of three-dimensional probability space (seven is the significant octant where all three values are above the $50 \%$ level). The weighted average angular separation is computed by the manner given in Appendix A. n.s. indicates not significant.*

\begin{tabular}{|c|c|c|c|c|c|c|c|c|c|c|c|c|c|c|c|c|}
\hline \multirow{2}{*}{$\begin{array}{l}\text { Period } \\
\text { (h) }\end{array}$} & \multirow{2}{*}{$\begin{array}{l}\text { Depth } \\
\text { (m) }\end{array}$} & \multirow{2}{*}{$\begin{array}{l}\text { Vari- } \\
\text { ance }\end{array}$} & \multirow{2}{*}{$\begin{array}{l}\text { Joint } \\
\text { proba- } \\
\text { bility* }\end{array}$} & \multirow{2}{*}{$\begin{array}{l}\text { Oc- } \\
\text { tant }\end{array}$} & \multicolumn{3}{|c|}{$553 \times 554$} & \multicolumn{3}{|c|}{$554 \times 555$} & \multicolumn{3}{|c|}{$555 \times 553$} & Geometr & ical angular se & parations \\
\hline & & & & & coh & $\mathrm{Ph}$ & $M$ & coh & $\mathrm{Ph}$ & $M$ & coh & $\mathrm{Ph}$ & $M$ & $553 \times 554$ & $554 \times 555$ & $555 \times 553$ \\
\hline 405 & 300 & $T$ & 20.1 & 7 & n.s. & & & n.s. & & & n.s. & & & & & \\
\hline & & L & 28.3 & 3 & n.s. & & & n.s. & & & n.s. & & & & & \\
\hline & & O & 0.8 & 6 & n.s. & & & n.s. & & & n.s. & & & & & \\
\hline & 1000 & $\mathrm{~T}$ & 1.6 & 7 & n.s. & 1 & & 0.52 & $148 \pm 39$ & & 0.47 & $14 \pm 46$ & & & & \\
\hline & & $\mathrm{L}$ & 0.1 & 7 & n.s. & & & n.s. & & & 0.63 & $-110 \pm 28$ & $-1 A B$ & & & \\
\hline & & o & 0.8 & 6 & n.s. & & & 0.55 & $-150 \pm 36$ & $-1 \mathrm{~A}$ & n.s. & & & & & \\
\hline & 1500 & $T$ & 15.4 & 2 & n.s. & & & 0.47 & $-70 \pm 46$ & & n.s. & & & ' & & \\
\hline 81.0 & 300 & $\mathrm{~T}$ & 0.8 & 7 & 0.52 & $146 \pm 39$ & -2 & n.s. & & & 0.55 & $-122 \pm 36$ & $-1 A B$ & $107 \pm 19.5$ & & \\
\hline & & $\mathrm{L}$ & 25.5 & 3 & n.s. & & & n.s. & & & n.s. & & & & & \\
\hline & & $\mathrm{O}$ & 1.0 & 3 & n.s. & & & 0.54 & $-173 \pm 37$ & $-2 \mathrm{~B}$ & n.s. & & & & $86.5 \pm 18.5$ & \\
\hline & 1000 & $\mathrm{~T}$ & 13.8 & 4 & n.s. & & & n.s. & & & n.s. & & & & & \\
\hline & & $\mathrm{L}$ & 22.8 & 7 & n.s. & & & n.s. & & & n.s. & & & & & \\
\hline & & 0 & 10.5 & 7 & n.s. & & & n.s. & & & n.s. & & & & & \\
\hline & 1500 & $\mathrm{~T}$ & 10.6 & 0 & n.s. & & & n.s. & & & 0.46 & $-46 \pm 48$ & & & & \\
\hline 54.0 & 300 & $\mathrm{~T}$ & 2.2 & 7 & n.s. & & & 0.50 & $96 \pm 42$ & $-2 \mathrm{~A}$ & n.s. & & & & & \\
\hline & & $\mathrm{L}$ & 16.2 & 4 & n.s. & & & n.s. & & & n.s. & & & & & \\
\hline & & O & 14.6 & 2 & n.s. & & & n.s. & & & n.s. & & & & & \\
\hline & 1000 & $T$ & 27.6 & 5 & n.s. & & & n.s. & & & n.s. & & & & & \\
\hline & & L & 0.4 & 3 & n.s. & & & 0.59 & $-145 \pm 32$ & $-1 \mathrm{~A}$ & n.s. & & & & $145 \pm 32$ & \\
\hline & & o & 8.3 & 7 & n.s. & & & 0.46 & $88 \pm 48$ & $-2 A$ & n.s. & & & & & \\
\hline & 1500 & $\mathrm{~T}$ & 4.2 & 4 & n.s. & & & n.s. & & & n.s. & & & & & \\
\hline 45.0 & 300 & $\mathrm{~T}$ & 1.4 & 7 & n.s. & & & n.s. & & & 0.53 & $-156 \pm 38$ & $-1 \mathrm{~A}$ & & & \\
\hline & & $\mathrm{L}$ & 2.9 & 7 & 0.45 & $-69 \pm 50$ & & 0.48 & $169 \pm 45$ & & 0.47 & $-146 \pm 47$ & $-1 \mathrm{~A}$ & & & \\
\hline & & 0 & 2.6 & 2 & n.s. & & & 0.49 & $-12 \pm 44$ & & n.s. & & & & & \\
\hline & 1000 & $\mathrm{~T}$ & 0.0 & 7 & 0.68 & $-31 \pm 25$ & $-3 A$ & n.s. & & & n.s. & & & & & \\
\hline & & L & 35.1 & 6 & n.s. & & & n.s. & & & n.s. & & & & & \\
\hline & & 0 & 9.2 & 6 & n.s. & & & n.s. & & & n.s. & & & & & \\
\hline & 1500 & $\mathrm{~T}$ & 26.6 & 3 & n.s. & & & n.s. & & & n.s. & & & & & \\
\hline 26.1 & 300 & $\mathrm{~T}$ & 27.6 & 7 & n.s. & & & n.s. & & & n.s. & & & & & \\
\hline & & L & 0.1 & 7 & n.s. & & & 0.65 & $-142 \pm 27$ & $-1 \mathrm{~A}$ & n.s. & & & & $142 \pm 27$ & \\
\hline & & O & 39.8 & 1 & n.s. & & & n.s. & & & n.s. & & & & & \\
\hline & 1000 & $\mathrm{~T}$ & 1.0 & 7 & 0.54 & $-145 \pm 37$ & $-1 \mathrm{AB}$ & 0.48 & $-130 \pm 45$ & $-1 \mathrm{~A}$ & n.s. & & & $145 \pm 37$ & & \\
\hline & & L & 1.2 & 4 & 0.53 & $-173 \pm 38$ & $-1 \mathrm{~B}$ & n.s. & & & 0.46 & $-172 \pm 48$ & $-2 \mathrm{~B}$ & & & \\
\hline & & o & 2.3 & 5 & n.s. & & & n.s. & & & 0.50 & $178 \pm 42$ & $-2 \mathrm{~B}$ & & & \\
\hline & 1500 & $T$ & 19.9 & 3 & n.s. & & & 0.51 & $-100 \pm 41$ & $-1 \mathrm{AB}$ & & & & & & \\
\hline 18.4 & 300 & $\mathrm{~T}$ & 1.0 & 7 & 0.54 & $156 \pm 37$ & $-7 \mathrm{~A}$ & n.s. & & & 0.50 & $71 \pm 42$ & $+7 \mathrm{~A}$ & $125 \pm 5.3$ & & \\
\hline & & L & 0.7 & 1 & n.s. & & & n.s. & & & 0.56 & $120 \pm 35$ & $+7 \mathrm{~A}$ & & & $120 \pm 5$ \\
\hline & & O & 27.4 & 2 & n.s. & & & n.s. & & & 0.48 & $109 \pm 45$ & $+7 \mathrm{~A}$ & & & \\
\hline & 1000 & $\mathrm{~T}$ & 3.4 & 2 & n.s. & & & 0,47 & $-59 \pm 47$ & & n.s. & & & & & \\
\hline & & L & 16.7 & 2 & n.s. & & & n.s. & . & & n.s. & & & & & \\
\hline & & 0 & 21.7 & 2 & n.s. & & & n.s. & & & n.s. & & & & & \\
\hline & 1500 & $T$ & 14.6 & 6 & n.s. & & & n.s. & & & n.s. & & & & & \\
\hline 14.2 & 1000 & $\mathrm{~T}$ & 5.1 & 7 & n.s. & & & n.s. & & & 0.45 & $-49 \pm 50$ & & & & \\
\hline & & $\mathrm{L}$ & 1.5 & 7 & 0.48 & $54 \pm 45$ & & 0.52 & $127 \pm 39$ & & n.s. & & & & & \\
\hline & & $\mathrm{O}$ & 0.7 & 3 & n.s. & & & 0.47 & $114 \pm 46$ & & 0.56 & $-110 \pm 35$ & $-7 \mathrm{~A}$ & & & $118.6 \pm 5$ \\
\hline & 300 & $T$ & 16.9 & 3 & n.s. & & & n.s. & & & n.s. & & & & & \\
\hline & & L & 30.5 & 1 & n.s. & & & n.s. & & & n.s. & & & & & \\
\hline & & o & 6.6 & 5 & n.s. & & & n.s. & & & n.s. & & & & & \\
\hline & 1500 & $\mathrm{~T}$ & 20.2 & 7 & n.s. & & & n.s. & & & n.s. & & & & & \\
\hline 11.7 & 300 & $\mathrm{~T}$ & 11.2 & 2 & n.s. & & & n.s. & & & n.s. & & & & & \\
\hline & & L & 17.6 & 4 & n.s. & & & 0.50 & $-93 \pm 42$ & & n.s. & & & & & \\
\hline & & O & 11.3 & 3 & n.s. & & & n.s. & & & n.s. & & & & & \\
\hline & 1000 & $\mathrm{~T}$ & 0.2 & 3 & n.s. & & & 0.61 & $106 \pm 30$ & $-6 B$ & n.s. & & & & & \\
\hline & & $\mathrm{L}$ & 0.1 & 7 & n.s. & & & n.s. & & & 0.64 & $-1 \pm 28$ & $\begin{array}{l} \pm 3 \mathrm{~A}, \\
\pm 6 \mathrm{~A}\end{array}$ & & & \\
\hline & & o & 8.7 & 1 & n.s. & & & n.s. & & & n.s. & - & & $=$ & & \\
\hline & 1500 & $T$ & 11.7 & 0 & n.s. & & & n.s. & & & n.s. & & & & & \\
\hline 10.4 & 300 & $T$ & 4.1 & 6 & n.s. & & & 0.46 & $-6 \pm 48$ & & n.s. & & & & & \\
\hline & & L & 6.3 & 7 & n.s. & & & 0.54 & $-144 \pm 37$ & $+6 \mathrm{~B}$ & n.s. & & & & $96 \pm 6.2$ & \\
\hline & & 0 & 0.7 & 7 & 0.56 & $-150 \pm 35$ & $+6 \mathrm{~B}$ & n.s. & & & n.s. & & & $155 \pm 5.8$ & & \\
\hline & 1000 & $T$ & 18.3 & 6 & n.s. & & & n.s. & & & n.s. & & & & & \\
\hline & & L & 1.1 & 3 & n.s. & & & n.s. & & & 0.54 & $162 \pm 37$ & $-5 \mathrm{~B}$ & . & & \\
\hline & & o & 10.6 & 3 & n.s. & & & n.s. & & & 0.46 & $-128 \pm 48$ & & & & \\
\hline & 1500 & $T$ & 6.3 & 5 & n.s. & & & n.s. & & & n.s. & & & & & \\
\hline
\end{tabular}


TABLE 4. (Continued)

\begin{tabular}{|c|c|c|c|c|c|c|c|c|c|c|c|c|c|c|c|c|}
\hline \multirow{2}{*}{$\begin{array}{l}\text { Period } \\
\text { (h) }\end{array}$} & \multirow{2}{*}{$\begin{array}{l}\text { Depth } \\
\text { (m) }\end{array}$} & \multirow{2}{*}{$\begin{array}{l}\text { Vari- } \\
\text { ance }\end{array}$} & \multirow{2}{*}{$\begin{array}{l}\text { Joint } \\
\text { proba- } \\
\text { bility* }\end{array}$} & \multirow{2}{*}{$\begin{array}{l}\text { Oc- } \\
\text { tant }\end{array}$} & \multicolumn{3}{|c|}{$553 \times 554$} & \multicolumn{3}{|c|}{$554 \times 555$} & \multicolumn{3}{|c|}{$555 \times 553$} & \multicolumn{3}{|c|}{ Geometrical angular separations } \\
\hline & & & & & coh & $\mathrm{Ph}$ & $M$ & coh & $\mathrm{Ph}$ & $M$ & coh & $\mathrm{Ph}$ & $M$ & $553 \times 554$ & $554 \times 555$ & $555 \times 553$ \\
\hline \multirow[t]{7}{*}{9.8} & 300 & $T$ & 6.9 & 2 & n.s. & & & n.s. & & & n.s. & & & & $120 \pm 8.3$ & \\
\hline & & $\mathrm{L}$ & 0.5 & 7 & n.s. & & & 0.58 & $-120 \pm 33$ & $-1 A B$ & n.s. & & & & & \\
\hline & & o & 39.1 & 4 & n.s. & & & n.s. & & & n.s. & & & & & \\
\hline & 1000 & $\mathrm{~T}$ & 1.0 & 2 & n.s. & & & n.s. & & & n.s. & & & & & \\
\hline & & L & 14.3 & 0 & n.s. & & & n.s. & & & n.s. & & & & & \\
\hline & & o & 22.4 & 6 & n.s. & & & n.s. & & & n.s. & & & & & \\
\hline & 1500 & $\mathrm{~T}$ & 4.2 & 3 & n.s. & & & n.s. & & & 0.48 & $1 \pm 45$ & & - & & \\
\hline \multirow[t]{7}{*}{8.3} & 300 & $\mathrm{~T}$ & 32.8 & 4 & n.s. & & & n.s. & & & n.s. & & & & & \\
\hline & & L & 14.8 & 6 & n.s. & & & n.s. & & & n.s. & & & & & \\
\hline & & o & 16.2 & 7 & n.s. & & & n.s. & & & n.s. & & & & & \\
\hline & 1000 & $\mathrm{~T}$ & 2.1 & 4 & n.s. & & & n.s. & & & n.s. & & & & & \\
\hline & & $\mathrm{L}$ & 0.4 & 7 & n.s. & 1 & & 0.59 & $158 \pm 32$ & $\pm 2 \mathrm{~B}$ & n.s. & & & & & \\
\hline & & o & $34.6^{\circ}$ & 4 & n.s. & & & n.s. & & & n.s. & & & & & \\
\hline & 1500 & $T$ & 3.3 & 4 & 0.48 & $163 \pm 45$ & & n.s. & & & n.s. & & & & & \\
\hline Weighte & average & & & & & & & & & & & & & $132 \pm 7.8$ & $110 \pm 4.7$ & $119.3 \pm 3.5$ \\
\hline
\end{tabular}

* $\mathrm{T}=$ temperature, $\mathrm{L}=$ longshore velocity, $\mathrm{O}=$ offshore velocity.

infinity of possible mode numbers and we have chosen the lowest mode consistent with subinertial motions traveling clockwise, superinertial ones in either direction, and modal determinations showing some degree of uniformity.

According to Hannon (1970) and Koopmans (1974), there is, in addition to the indicated phase errors which are bounded by $\pm 90^{\circ}$, an additional

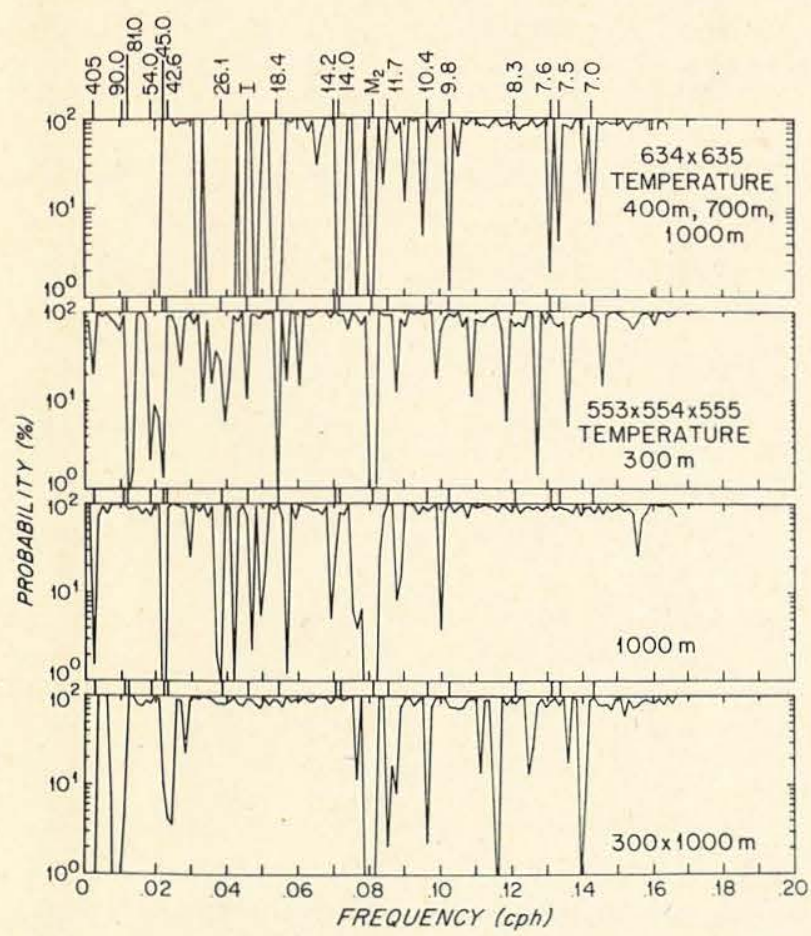

FIG. 6. Joint probabilities that the coherence amplitudes between the three indicated pairs are a result of random fluctuations. The true $95 \%$ level is at a probability of $7.8 \%$. possibility of an error in both the sign of the cospectrum and quadrature spectrum which increases in probability as the coherence decreases. We have chosen to use only the phase estimates that have coherence amplitudes in excess of the $99 \%$ confidence level and these are indicated by bold type on Tables 4 and 5 .

Even with the above restriction on the phase information there is not total consistency among the various mode number computations at each period. Subinertial frequencies tend to be of low mode (first or second), whereas superinertial frequencies range to higher modes of both propagation senses. With some exceptions the A model elliptic geometry seems favored.

Where some consistency exists we have used the mode number and phases to compute angular separations between moorings and these are given as the last columns on Tables 4 and 5. The weighted averages of these estimates (computed by a method given in Appendix A) are given at the bottom of the columns. Not surprisingly these averages fall somewhere between the models $\mathrm{A}$ and $\mathrm{B}$.

\section{d. Vertical cross spectra}

In Fig. 8 we show coherence amplitudes and phases for temperature between 700 and $1000 \mathrm{~m}$ on the near-field array. Note the significantly nonzero amplitudes especially in the subinertial band at those frequencies that have been identified with azimuthal modes and the tendency of the phases to be pegged at $0^{\circ}$ or $\pm 180^{\circ}-\mathrm{a}$ strong indication of vertical modal structure.

Information on vertical phases is summarized in Tables 7 and 8 . In the far field we have estimated the lowest vertical mode number consistent with 
TABLE 5. Coherence and phase information for the longshore segment of the near-field array. See Table 4 caption for details.

\begin{tabular}{|c|c|c|c|c|c|c|c|c|}
\hline \multirow{2}{*}{$\begin{array}{l}\text { Period } \\
\text { (h) }\end{array}$} & \multirow{2}{*}{$\begin{array}{c}\text { Depth } \\
\text { (m) }\end{array}$} & \multirow{2}{*}{$\begin{array}{l}\text { Vari- } \\
\text { able }\end{array}$} & \multirow{2}{*}{$\begin{array}{c}\text { Joint } \\
\text { proba- } \\
\text { bility }\end{array}$} & \multirow[b]{2}{*}{ Octant } & \multicolumn{2}{|c|}{$635 \times 634$} & \multirow[b]{2}{*}{$M$} & \multirow{2}{*}{$\begin{array}{c}\text { Geometrical } \\
\text { angular } \\
\text { separation }\end{array}$} \\
\hline & & & & & coh & $\mathrm{Ph}$ & & \\
\hline 405 & $\begin{array}{r}400 \\
700 \\
\\
1000\end{array}$ & $\begin{array}{l}\mathrm{T} \\
\mathrm{T} \\
\mathrm{L} \\
\mathrm{O} \\
\mathrm{T}\end{array}$ & 0.0 & 7 & $\begin{array}{l}0.69 \\
0.85 \\
\text { n.s. } \\
0.44 \\
0.99\end{array}$ & $\begin{aligned}-14 & \pm 20 \\
-8 & \pm 11 \\
-161 & \pm 42 \\
-1 & \pm 2\end{aligned}$ & & \\
\hline 90.0 & $\begin{array}{l}400 \\
700\end{array}$ & $\begin{array}{l}\mathrm{T} \\
\mathrm{T} \\
\mathrm{L} \\
\mathrm{O} \\
\mathrm{T}\end{array}$ & 0.0 & 7 & $\begin{array}{l}0.59 \\
0.79 \\
0.76 \\
\text { n.s. } \\
0.66\end{array}$ & $\begin{array}{l}-109 \pm 26 \\
-106 \pm 14 \\
-102 \pm 16 \\
-100 \pm 22\end{array}$ & $\begin{array}{l}-2 \mathrm{~A} \\
-2 \mathrm{~A} \\
-2 \mathrm{~A} \\
-2 \mathrm{~A}\end{array}$ & $\begin{array}{l}54 \pm 13 \\
53 \pm 7 \\
51 \pm 8 \\
50 \pm 11\end{array}$ \\
\hline 54.0 & $\begin{array}{l}400 \\
700\end{array}$ & $\begin{array}{l}\mathrm{T} \\
\mathrm{T} \\
\mathrm{L} \\
\mathrm{O} \\
\mathrm{T}\end{array}$ & 0.0 & 7 & $\begin{array}{l}0.52 \\
0.74 \\
0.81 \\
0.48 \\
\\
0.61\end{array}$ & $\begin{array}{r}-112 \pm 31 \\
-81 \pm 17 \\
-86 \pm 14 \\
-75 \pm 37 \\
-47 \pm 25\end{array}$ & $\begin{array}{l}-2 \mathrm{~A} \\
-2 \mathrm{~B} \\
-2 \mathrm{~B} \\
-1 \mathrm{AB} \\
-2 \mathrm{AB} \\
-1 \mathrm{AB}\end{array}$ & \\
\hline 42.6 & $\begin{array}{r}400 \\
700 \\
\\
1000\end{array}$ & $\begin{array}{l}\mathrm{T} \\
\mathrm{T} \\
\mathrm{L} \\
\mathrm{O} \\
\mathrm{T}\end{array}$ & 0.0 & 6 & $\begin{array}{l}\text { n.s. } \\
\text { n.s. } \\
0.47 \\
\text { n.s. } \\
0.63\end{array}$ & $\begin{array}{r}-111 \pm 38 \\
-93 \pm 24\end{array}$ & $-2 \mathrm{AB}$ & $\begin{array}{l}55.5 \pm 19 \\
46.5 \pm 12\end{array}$ \\
\hline 26.1 & $\begin{array}{l}400 \\
700\end{array}$ & $\begin{array}{l}\mathrm{T} \\
\mathrm{T} \\
\mathrm{L} \\
\mathrm{O} \\
\mathrm{T}\end{array}$ & 0.0 & 7 & $\begin{array}{l}0.86 \\
0.89 \\
0.76 \\
\text { n.s. } \\
0.61\end{array}$ & $\begin{aligned}-129 & \pm 11 \\
-60 & \pm 9 \\
165 & \pm 16 \\
-102 & \pm 26\end{aligned}$ & $\begin{array}{l}-2 \mathrm{~A} \\
-1 \mathrm{~A} \\
-3 \mathrm{~A} \\
-2 \mathrm{~A} \\
-3 \mathrm{~B}\end{array}$ & \\
\hline 18.4 & $\begin{array}{r}400 \\
700 \\
\\
1000\end{array}$ & $\begin{array}{l}\mathrm{T} \\
\mathrm{T} \\
\mathrm{L} \\
\mathrm{O} \\
\mathrm{T}\end{array}$ & 0.2 & 7 & $\begin{array}{l}\text { n.s. } \\
0.40 \\
0.45 \\
\text { n.s. } \\
0.54\end{array}$ & $\begin{array}{r}-27 \pm 49 \\
-126 \pm 40 \\
-25 \pm 31\end{array}$ & $+7 \mathrm{~A}$ & $48 \pm 4.5$ \\
\hline 14.0 & $\begin{array}{r}400 \\
700 \\
1000\end{array}$ & $\begin{array}{l}\mathrm{T} \\
\mathrm{T} \\
\mathrm{L} \\
\mathrm{O} \\
\mathrm{T}\end{array}$ & 0.0 & 7 & $\begin{array}{l}\text { n.s. } \\
0.62 \\
\text { n.s. } \\
\text { n.s. } \\
0.47\end{array}$ & $\begin{array}{r}10 \pm 25 \\
-59 \pm 38\end{array}$ & $\begin{array}{l}-7 \mathrm{~A} \\
-7 \mathrm{~A}\end{array}$ & $\begin{array}{l}50 \pm 5 \\
60 \pm 5.5\end{array}$ \\
\hline 11.7 & Not sig & & & & & & & \\
\hline 10.5 & $\begin{array}{l}400 \\
700\end{array}$ & $\begin{array}{l}\mathrm{T} \\
\mathrm{T} \\
\mathrm{L} \\
\mathrm{O} \\
\mathrm{T}\end{array}$ & 4.8 & 7 & $\begin{array}{l}\text { n.s. } \\
\text { n.s. } \\
0.41 \\
\text { n.s. } \\
\text { n.s. }\end{array}$ & $-142 \pm 47$ & $+6 \mathrm{~B}$ & $36.3 \pm 8.0$ \\
\hline 9.8 & $\begin{array}{l}400 \\
700\end{array}$ & $\begin{array}{l}\mathrm{T} \\
\mathrm{T} \\
\mathrm{L} \\
\mathrm{O} \\
\mathrm{T}\end{array}$ & 1.2 & 7 & $\begin{array}{l}0.47 \\
\text { n.s. } \\
\text { n.s. } \\
\text { n.s. } \\
\text { n.s. }\end{array}$ & $149 \pm 38$ & $-4 \mathrm{~A}$ & $52.8 \pm 9.5$ \\
\hline $\begin{array}{l}8.3 \\
7.6 \\
7.5 \\
7.0\end{array}$ & Not sig & & $\begin{array}{l}1.9 \\
4.2 \\
6.4\end{array}$ & $\begin{array}{l}7 \\
7 \\
7\end{array}$ & & & & \\
\hline
\end{tabular}

the observations through a comparison of the indi- modes are shown in Fig. 9 for a Brunt-Väisälä cated velocity and temperature nodal depths with those computed for flat-bottom baroclinic modes in profile taken from an average of 10 CTD stations surrounding the island in October-November 1975 an ocean of $4500 \mathrm{~m}$ depth. The first four such (Sanford and Hogg, 1977). Except for an indication 


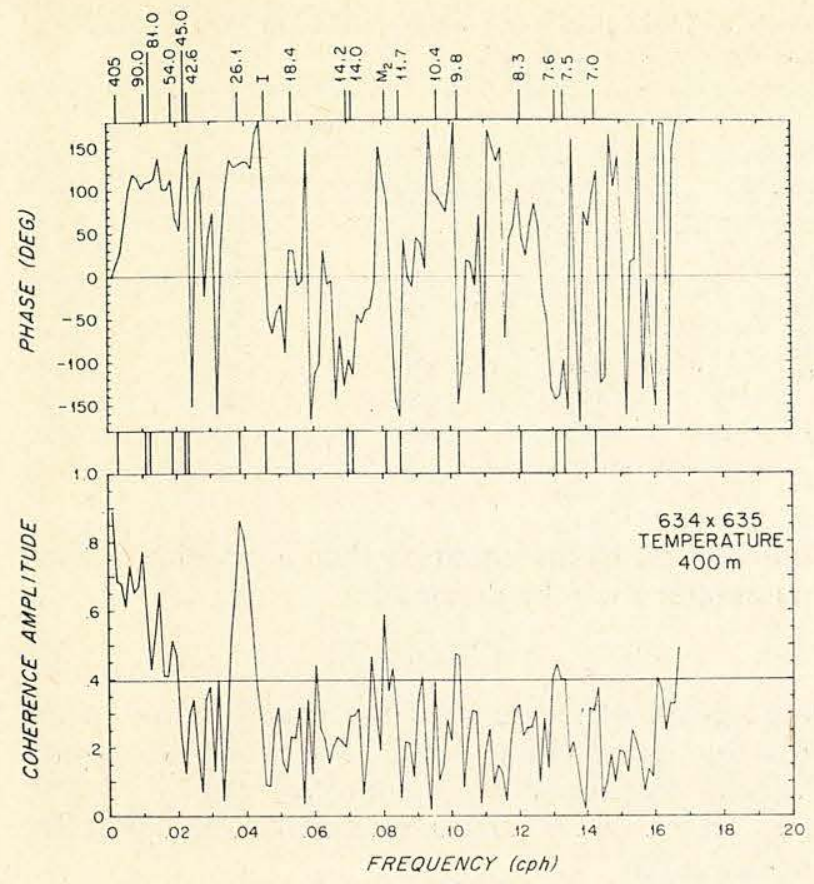

a

FIG. 7. Near-field azimuthal coherence amplitude and phase for temperature at (a) $400 \mathrm{~m}$, (b) $700 \mathrm{~m}$ and (c) $1000 \mathrm{~m}$ depth.

of the second vertical mode at $45.0 \mathrm{~h}$ the rest of the subinertial modes suggest the fundamental. Superinertial modes are more scattered with mode numbers as high as 5 at $8.3 \mathrm{~h}$.

The near-field array is situated in a region of strong bottom slope where it cannot be expected that the deep-water flat-bottom modes should concisely describe the vertical structure although we shall give arguments in the next section to support their use in the far field. For the subinertial bands we have empirically established a mode number through inspection of the indicated nodal positions in the temperature observations. At $26.1 \mathrm{~h}$ there are no observed nodes consistent with a fundamental mode. At both 45.0 and $54.0 \mathrm{~h}$ one node is indicated and as this is deeper for $54.0 \mathrm{~h}$ we have called $54.0 \mathrm{~h}$ the second mode and $45.0 \mathrm{~h}$ the third. At $90.0 \mathrm{~h}$ there are two nodes and this is termed the fourth mode. At $405 \mathrm{~h}$, the temperature phases are consistent with the first mode description, but the velocity phases are not. The superinertial modes have been established by comparison.

Not all the phases in Tables 7 and 8 are indistinguishable from $0^{\circ}$ or $\pm 180^{\circ}$. Some of these nonmode-like phases are undoubtedly caused by estimates lying on the fringes of their distributions but some may also be real. In the next section we shall show that at $26.1 \mathrm{~h}$ the phases (azimuthal and vertical) are better explained by two phase-locked modes. In addition, it must be recognized that pure azimuthal and vertical modes arise only in separable
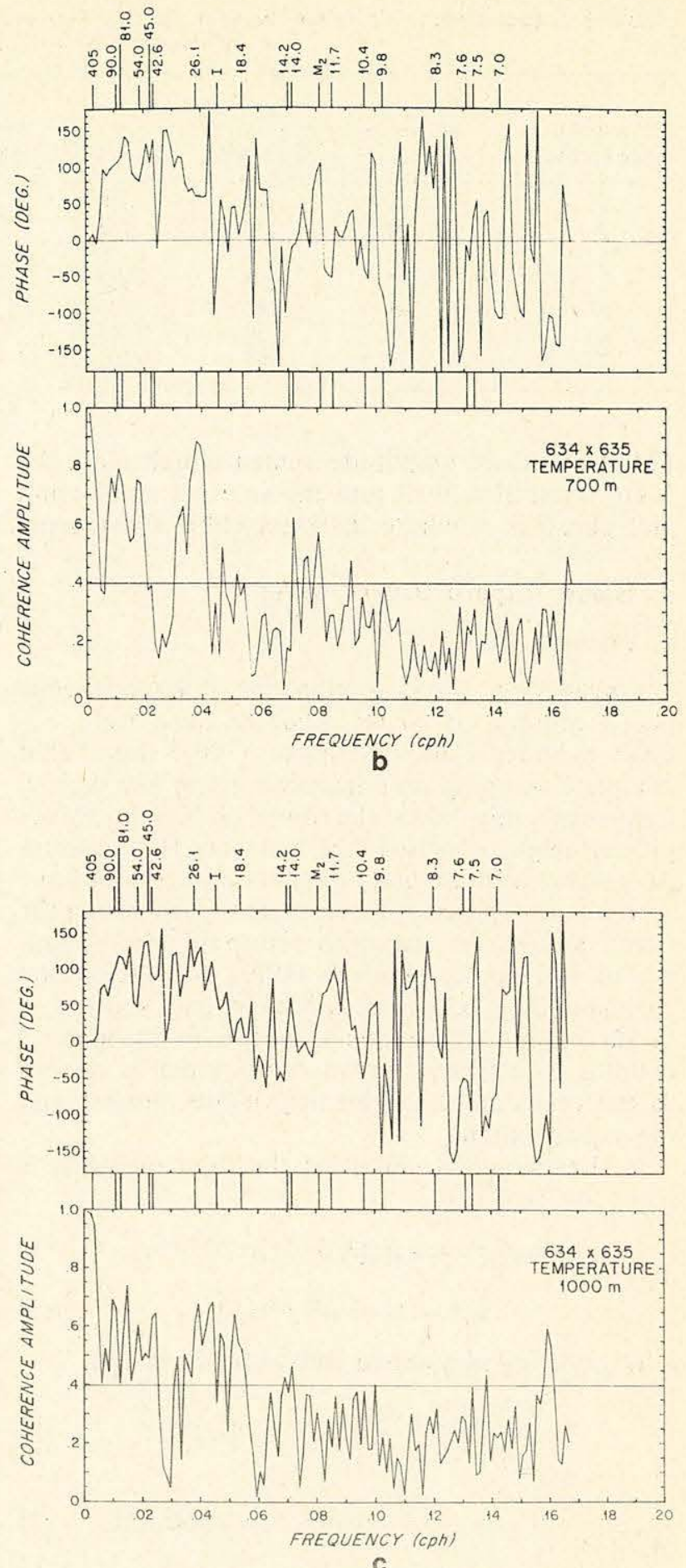

geometry - which, of course, Bermuda is not. We should, therefore, expect only an approximation of the separable modal structure.

\section{e. Radial cross spectra}

Fig. 10 shows coherence amplitude and phase of temperature at $1000 \mathrm{~m}$ between moorings 633 and 
TABLE 6. Expected phase separations between mooring pairs as a function of azimuthal mode number and elliptic model geometry. For counterclockwise motion the signs must be changed.

\begin{tabular}{|c|c|c|c|c|c|c|c|c|}
\hline \multirow{2}{*}{$\begin{array}{c}\text { Azimuthal } \\
\text { mode number }\end{array}$} & \multicolumn{4}{|c|}{ Model A } & \multicolumn{4}{|c|}{ Model B } \\
\hline & $553 \times 554$ & $554 \times 555$ & $555 \times 553$ & $635 \times 634$ & $553 \times 554$ & $554 \times 555$ & $555 \times 553$ & $635 \times 634$ \\
\hline 1 & $-128^{\circ}$ & $-115^{\circ}$ & -118 & -59.4 & $-157^{\circ}$ & $-98^{\circ}$ & -106 & -37.3 \\
\hline 2 & 104 & 130 & 124 & -119 & 46 & 164 & 148 & -74.6 \\
\hline 3 & -24 & 15 & 6 & -178 & -111 & 66 & 42 & -112 \\
\hline 4 & -152 & -100 & -112 & 122 & 92 & -32 & -64 & -149 \\
\hline 5 & 80 & 145 & 130 & 63 & -65 & -130 & -170 & 173 \\
\hline 6 & -48 & 30 & 12 & 3 & 138 & 132 & 84 & 136 \\
\hline 7 & -176 & -85 & -106 & -57 & -19 & 34 & -22 & 100 \\
\hline
\end{tabular}

634. Coherence amplitude remains high over the $3 \mathrm{~km}$ separation well into the internal wave band and phase is nowhere distinguishable from zero.

\section{Island trapped Kelvin waves? \\ a. Theory}

Considering wave motion in a homogeneous ocean around an island modeled as a right circular cylinder Longuet-Higgins (1969) found that complete trapping only happens below the inertial frequency: this takes the form of Kelvin waves propagating clockwise in the Northern Hemisphere. At certain discrete frequencies these waves have an integral number of wavelengths surrounding the island and travel round to return in phase leading to resonance. Wunsch (1972) considered the corresponding baroclinic problem and showed it to be essentially identical to the barotropic by defining an effective ocean depth which is related to the real depth, the vertical mode number and the stratification.

In the baroclinic situation the fluid pressure is given by $(\omega<f)$

with

$$
p(r, \theta, z)=u_{m}(z) K_{n}\left(k_{m} r\right) e^{-i(n \theta+\omega t)},
$$

$$
k_{m}{ }^{2}=\left(1-\omega^{2} / f^{2}\right) \lambda_{m}{ }^{2},
$$

$K_{n}\left(k_{m} r\right)$ being a modified Bessel function and

$$
\begin{gathered}
\frac{\partial}{\partial z}\left[\frac{f^{2} u_{m}{ }^{\prime}(z)}{N^{2}(z)}\right]=-\lambda_{m}{ }^{2} u_{m}(z), \\
\frac{\partial}{\partial z} u_{m}=0 \text { on } z=0 \text { (top), }-H \text { (bottom), }
\end{gathered}
$$

describing the vertical modal structure. In order to satisfy the boundary condition of no normal velocity on the vertical island sides $(r=a)$,

$$
\left(\frac{\omega}{f}\right) k_{m} K_{n}{ }^{\prime}\left(k_{m} a\right)=-\left(\frac{n}{a}\right) K_{n}\left(k_{m} a\right),
$$

which with (5)-(7) establishes the dispersion relation. Treating $\lambda_{m}$ as a variable to be determined from the vertical modal equation then a nondimensional parameter $\epsilon$ can be defined by

$$
\epsilon=\left(a \lambda_{m}\right)^{2},
$$

the square of the ratio of the island radius to the Rossby deformation scale. For constant BruntVäisälä frequency $\lambda_{m}=m \pi f / N H$ and $\epsilon=(a f)^{2 /}$ $g h_{e}$, where $g h_{e}=g^{\prime} H /(m \pi)^{2}$ and $h_{e}$ is the effective ocean depth.

\section{b. The dispersion relation}

Solutions to the dispersion relation (8) as a function of azimuthal mode number and $\epsilon$ are shown in Fig. 11. As was noted by Longuet-Higgins (1969) for sufficiently small islands only the first azimuthal mode can exist as a barotropic trapped wave. In

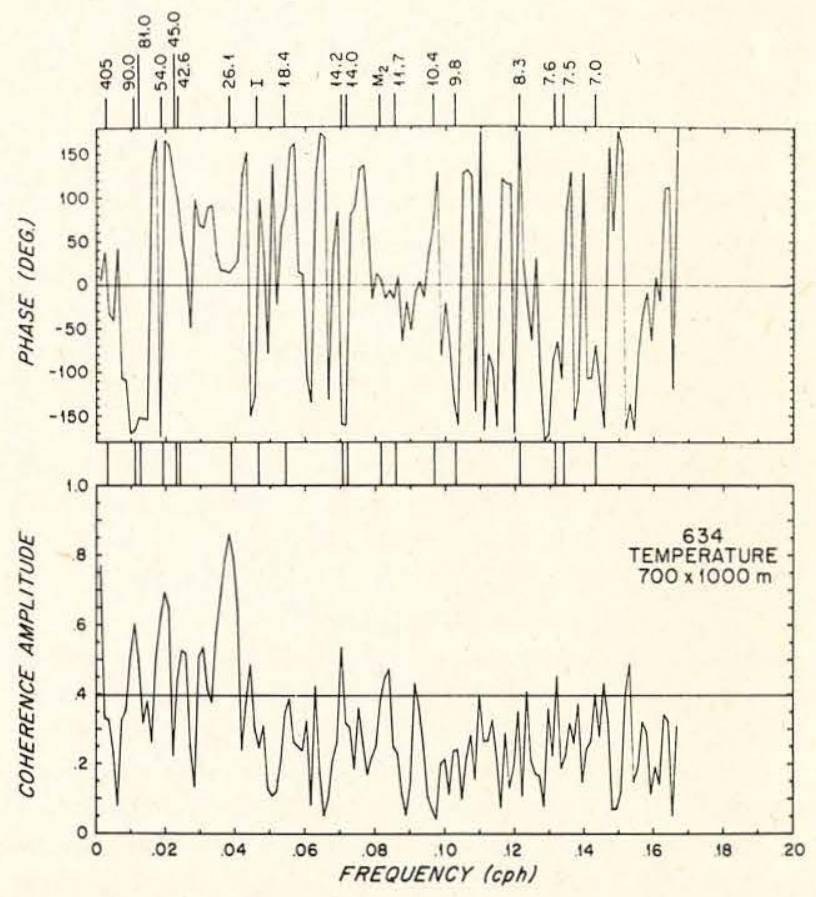

FIG. 8. Vertical coherence amplitude and phase between 700 and $1000 \mathrm{~m}$ depth on 634 for temperature. 
TABLE 7. Vertical coherence amplitudes (in parentheses) and phases for the far-field array at these periods satisfying the significance test.

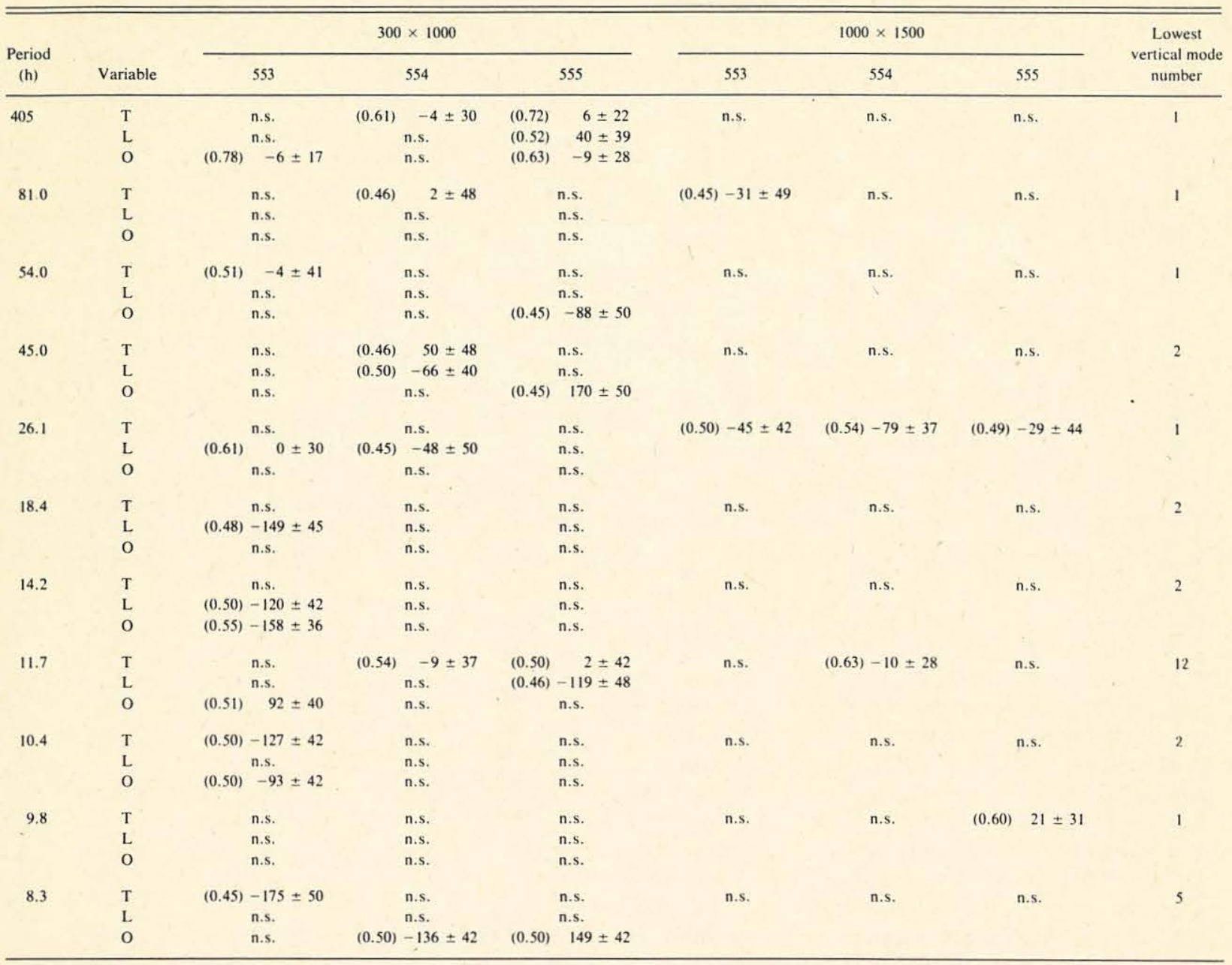

the baroclinic case, however, not only is $\epsilon$ larger because $h_{e} \ll H$ but it also increases with increasing vertical mode number $\left(\epsilon \propto m^{2}\right)$. Even if the lowest baroclinic mode can only exist as the lowest azimuthal mode, the higher azimuthal modes may be present as higher vertical modes.

Also shown on the frequency axis of Fig. 11 are the frequency ranges corresponding to the four subinertial bands in Tables 4 and 5 ( 82 and 90 , and 45.0 and 42.6 being lumped together and 405 being ignored). These bands are also indicated on the dispersion curves, themselves, the appropriate azimuthal curve being taken from Tables 4 and 5 .

For the Kelvin wave interpretation to be valid the values of $\epsilon$ corresponding to the emphasized portions of the curves on Fig. 11 should be determined by the values of $\lambda_{m}$ for the appropriate vertical modes. Fig. 9 illustrates the flat bottom baroclinic modes and in Table 9 are listed the corresponding Rossby deformation scales $\lambda_{m}{ }^{-1}$ versus mode number $m$ and the resulting values of $\epsilon^{1 / 2}$.
The island radius $a$ is taken to be the average of the major and minor axes of the ellipse determined by interpretation $A$ in Table $2[a=(14+24)$ / $2=19 \mathrm{~km}$. These values of $\epsilon^{1 / 2}$ are shown on Fig. 11. The first two vertical modes are close to the expected values but there is an increasing discrepancy with mode number.

Radial decay scales become much smaller with increasing mode number, a graphic illustration of which is given in Fig. 12 where they are superimposed on two radial bathymetric profiles of the island. Clearly, the vertical coast model is not bad for the lowest mode but becomes increasingly poor for the higher modes.

\section{c. Slope effects}

There is no general theory for wave trapping round islands in a stratified ocean over a sloping bottom although some progress has been made along straight coasts, most notably through use of numeri- 


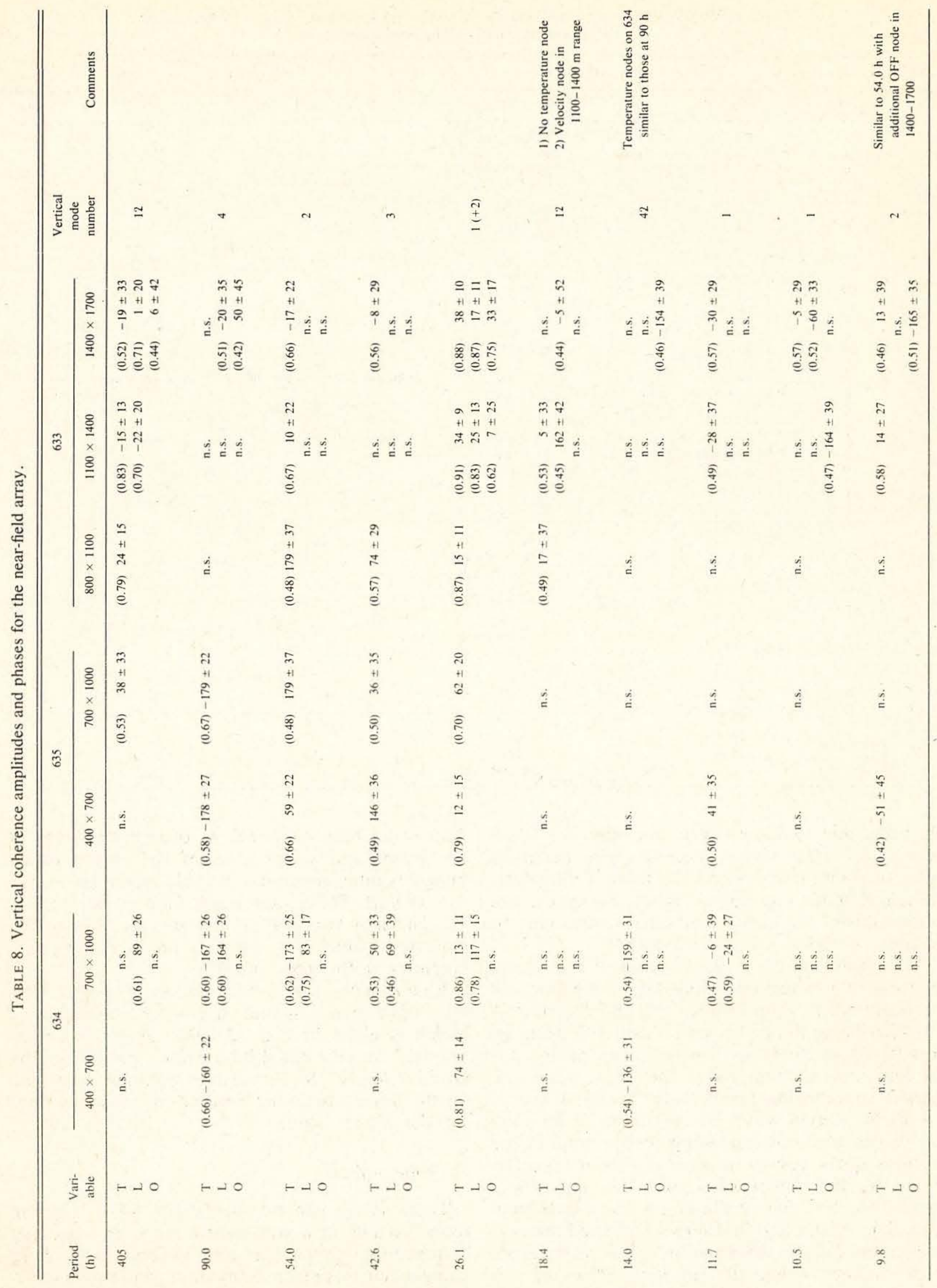




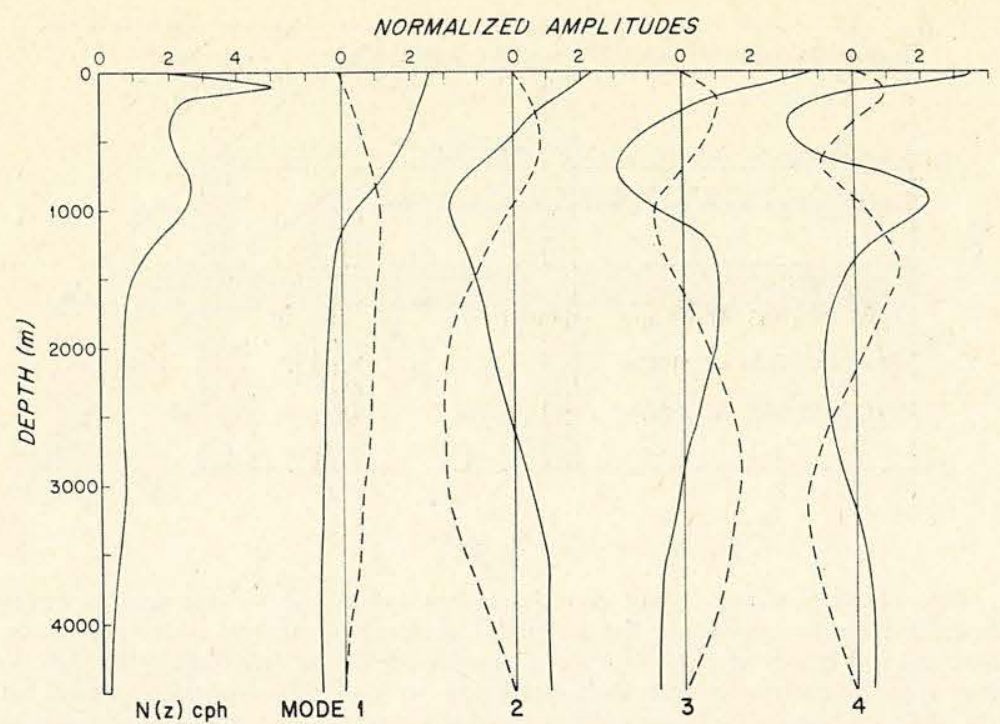

FIG. 9. Computed baroclinic wave modes in a flat-bottomed ocean of $4500 \mathrm{~m}$ depth. Left profile is the Brunt-Väisälä frequency, while the next four are horizontal velocity (solid) and vertical velocity (dashed) normalized to have unit integrated variance.

cal models (e.g., Wang and Mooers, 1976; Huthnance, 1978). Huthnance does conclude that when the stratification is strong, vertical motions will be inhibited and the trapped motions can be considered to be Kelvin-like but distorted by the geometry. At the other extreme, motions will be more barotropic with the offshore modal structure characteristic of

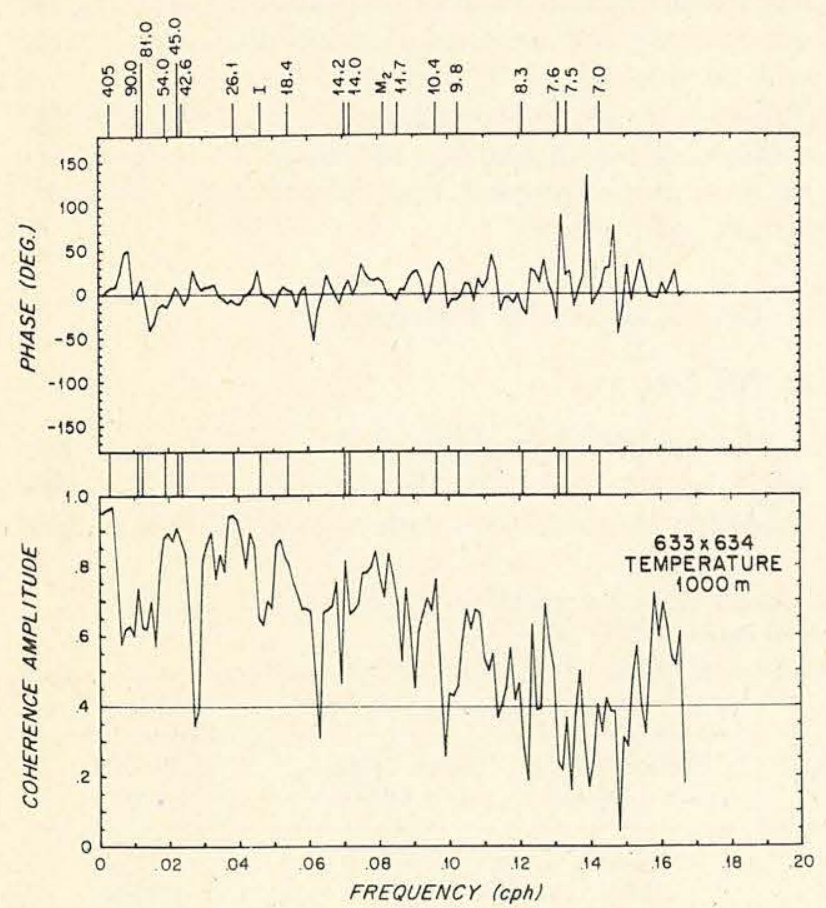

FIG. 10. Radial coherence amplitude and phase between 633 and 634 at $1000 \mathrm{~m}$ depth for temperature. the so-called shelf waves studied by Mysak (1967), Rhines (1969) and Longuet-Higgins (1970).

We see no evidence of offshore modal structure over the $3 \mathrm{~km}$ separation between 633 and 634 but strong support for vertical modes. As an aid to describing this vertical structure, we have taken the values of $\epsilon$ suggested for the empirical vertical modes from Fig. 9 and asked the question, "If these are similar to flat-bottom modes, to what bottom depth do they correspond?"

The question can be answered easily through use of the WKB approximation to (6) and (7):

where

$$
u_{m}(z) \approx N(z)^{1 / 2} \cos \left[\lambda_{m}^{f} \int_{0}^{z} \frac{N(z)}{f} d z\right],
$$

$$
\lambda_{m}^{f}=m \pi\left[\int_{0}^{H_{m}} \frac{N(z)}{f} d z\right]^{-1}
$$

is the value determined empirically and given in the second column of Table 9 and $H_{m}$ is determined by integrating $N(z) / f$ with depth until (11) is satisfied. The resulting bottom depths are given in the last column of Table 9 and shown schematically in Fig. 12 along with the appropriate decay scale.

As an alternative to the flat-bottom assumption the bottom boundary condition on a sloping boundary can be written as

$$
\frac{i \omega}{N^{2}} p_{z}=\frac{h_{r}}{\omega^{2}-f^{2}}\left(\frac{f}{r} p-i \omega p_{r}\right)
$$

on

$$
z=-h(r)
$$




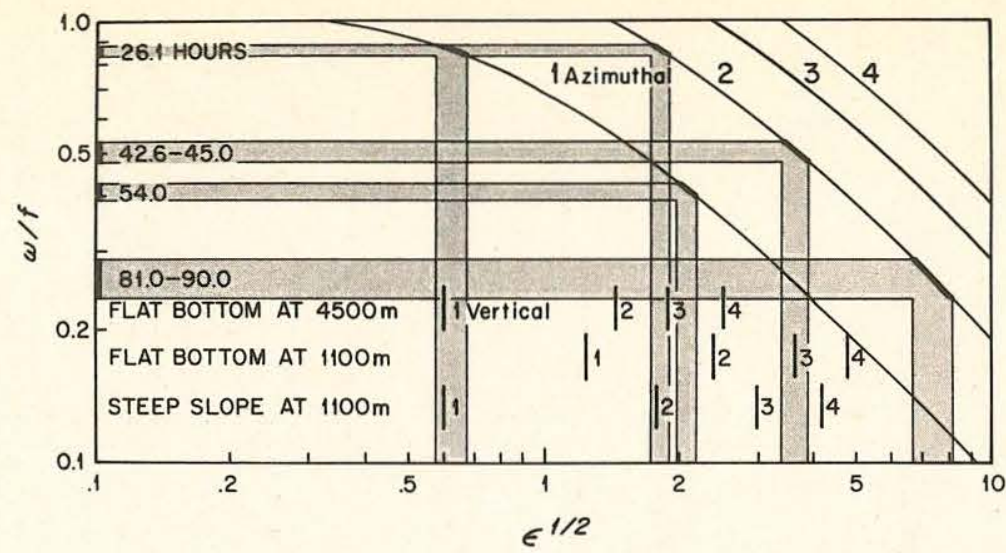

FIG. 11. Continuous curves give dependence of $\omega / f$ on $\epsilon^{1 / 2}$ for Kelvin waves in a flat-bottomed ocean for the azimuthal modes 1-4. Shown on the frequency axis are the bands of observed wave motion which are transferred laterally to the appropriate curve and then vertically to give corresponding values of $\epsilon^{1 / 2}$. Also shown are the values of $\epsilon^{1 / 2}$ for vertical modes $1-4$ determined for three versions of the bottom boundary condition.

For $\omega \ll f$ and $p \propto F(r, z) e^{-i n \theta}$ this can be approximated by

$$
\frac{\omega}{N^{2}} F_{z}=\frac{h_{r}}{f} \frac{n}{r} F \quad \text { on } \quad z=-h(r) .
$$

With the WKB approximation (10) the eigenvalue problem becomes

with

$$
\gamma_{m} \tan \gamma_{m}=-\frac{n h_{r}}{r} \frac{N(-h)}{\omega} \int_{0}^{-h} \frac{N}{f} d z,
$$

$$
\gamma_{m}=\lambda_{m}^{s} \int_{0}^{-h} \frac{N}{f} d z .
$$

At $h=1000 \mathrm{~m}, h_{r} \approx-0.2, N(-h) / \omega \approx 10^{2}, r \approx 20$ $\mathrm{km}$, and $\int_{0}^{-h} N / f d z \approx 44 \mathrm{~km}$. The right-hand side of (14) is much less than unity, yielding $\gamma_{m}$ that are approximately integral multiples of $\pi / 2$ so that

$$
\lambda_{m}^{s} \approx\left(\frac{2 m-1}{2}\right) \pi\left[\int_{0}^{-h} \frac{N(z)}{f} d z\right]^{-1} .
$$

The pressure perturbation and offshore velocity have nodes at the bottom where the temperature is a maximum. These modes are similar to the low- frequency baroclinic wave modes modified by sloping topography discussed by Rhines (1970) and Suarez (1971). In Table 9 and Fig. 11 we show values of $\epsilon^{1 / 2}=a \lambda_{m}^{s}$ computed from (16): there is reasonable agreement with the empirical values at azimuthal modes $1-3$ but the fourth is underestimated.

Whatever the vertical structure that is established over the sloping region, it must be joined to a sum of flat-bottom modes where the slope ends. At subinertial frequencies the lowest mode has the largest decay scale and we would expect that the far field will be dominated by low modes, consistent with Table 7. At superinertial frequencies the far-field motions are propagating, radiating waves and will retain a more complex vertical structure, also consistent with Table 7.

\section{Details of modal structure \\ a. 405 hours}

The observed motions at this period are somewhat of a puzzle. In the far field the available

\begin{tabular}{|c|c|c|c|c|c|c|}
\hline \multirow[b]{2}{*}{$\begin{array}{l}\text { Mode } \\
m\end{array}$} & \multirow[b]{2}{*}{$\begin{array}{c}\text { Decay scale } \\
\lambda_{m}{ }^{-1}\end{array}$} & \multicolumn{4}{|c|}{$\epsilon^{1 / 2}=a \lambda_{m}$} & \multirow{2}{*}{$\begin{array}{c}H_{\text {est }} \\
\text { Flat bottom } \\
\text { WKB } \\
\text { (m) }\end{array}$} \\
\hline & & $\begin{array}{c}\text { Empirical } \\
\qquad\left(a \lambda_{m}\right)\end{array}$ & $\begin{array}{l}\text { Flat bottom } \\
H=4500 \mathrm{~m}\end{array}$ & $\begin{array}{l}\text { Flat bottom } \\
H=1100 \mathrm{~m}\end{array}$ & $\begin{array}{l}\text { Steep slope } \\
H=1100 \mathrm{~m}\end{array}$ & \\
\hline 1 & $32 \mathrm{~km}$ & 0.6 & 0.6 & 1.2 & 0.6 & $>4500$ \\
\hline 2 & 9.5 & 2.0 & 1.44 & 2.4 & 1.8 & 1540 \\
\hline 3 & 5.4 & 3.5 & 1.88 & 3.3 & 3.0 & 1100 \\
\hline 4 & 2.7 & 7.0 & 2.52 & 4.7 & 4.2 & 740 \\
\hline
\end{tabular}
evidence is consistent with a first azimuthal, first

TABLE 9. Offshore decay scale, values of $\epsilon^{1 / 2}$ for various models of the bottom slope, and estimated effective bottom depth versus vertical mode number $M$. 
vertical mode. However, the later near-field observations give zero phase shift in the azimuth as well as the vertical indicating neither a first azimuthal nor a first vertical (the velocity should have a node above $1700 \mathrm{~m}$ - see Table 8 and Fig. 10). Of course, it is entirely plausible that trapped motions with this period existed during the exposure of 553-555 but not 633-634 and the strong coherence observed during this later time was more a feature of the mesoscale continuum than islandtrapped motions. We also note that waves of this period and modal character do not fit on the Kelvin wave dispersion curves of Fig. 12, suggesting topographic wave dynamics if they are trapped waves.

It is also possible to interpret the earlier measurements as a mesoscale wave field propagating to the west-southwest with a wavelength on the order of twice the separation distance between 554 and 555 or $\sim 200 \mathrm{~km}$ - not inconsistent with MODE results (Richman et al., 1977). The later observations should then have phase shifts of about $-40^{\circ}$ which is statistically distinguishable from the nearzero values observed.

\section{b. $90.0-81.0$ hours}

We lump these periods from the far- and near-field arrays together as they are at neighboring frequency estimates which, because the spectra have been hanned, are not independent. Some shift in resonant frequencies could be expected through long-term changes in the Brunt-Väisälä frequency or Doppler-shifts from low-frequency currents. These changes will be most felt by the slower moving, higher azimuthal modes.

Azimuthal phases in the far field in this band are not terribly consistent. However, the near-field results are very stable and indicate the second azimuthal mode.

In Fig. 13a we show the amplitude and phases versus depth for each mooring in the near-field array. The temperature spectra have been scaled so that they overlay in the $7-8 \mathrm{~h}$ frequency bandan empirical estimation of the WKB scaling. The shallower information on 634 has been transferred onto the plot for 633 where their profiles are compared with WKB vertical modes computed with $\lambda_{m}$ from Table 9 and the surface boundary condition. Considering the nonseparability of the geometry this WKB approximation does surprisingly well and supports our identification of the fourth mode.

\section{c. 54.0 hours}

The azimuthal phase information at this period is rather scattered with both first and second modes suggested. However, the vertical structure, illustrated in Fig. 13b, is indicative of the second

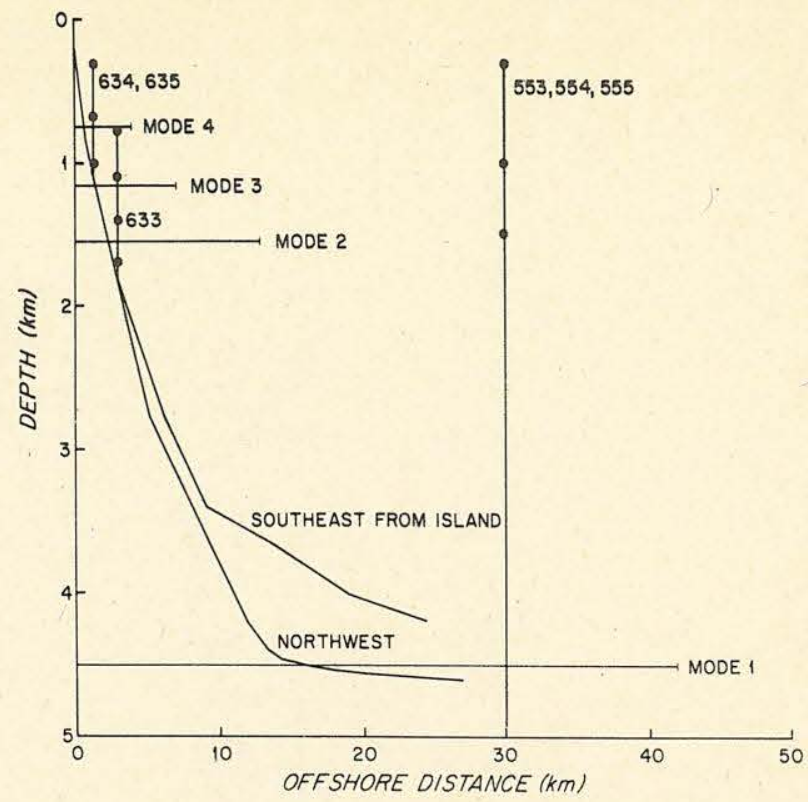

FIG. 12. Depth versus offshore distance along two lines radiating from Bermuda. Also shown are sketches of the mooring configurations and calculated effective bottom depths and offshore decay scales for the different vertical modes.

vertical mode and for consistency with the dispersion curves of Fig. 11 we favor the first azimuthal mode. The vertical structure is not as clear as that in the 81-90 hour bands as there are significant non-modal phase shifts between 400 and $700 \mathrm{~m}$ on moorings 634 and 635 , both indicating that the shallower depth lags the deeper by $60-80^{\circ}$. We are not sure what to make of this phase lag except to say that it could be a result of the nonseparable geometry. The WKB approximation to the vertical structure predicts a somewhat shallower zero crossing than is observed.

\section{d. 45.0-42.6 hours}

Once again these are neighboring estimates and we have lumped them together. The second azimuthal mode is suggested by the near-field array but the far field data shows little consistency with modes 1-3 all being indicated.

The vertical structure is in reasonable agreement with the WKB approximation, especially if one places a node in the $1100-1400 \mathrm{~m}$ depth range where the coherence amplitude is insignificant at the $95 \%$ level. The phase between 800 and $1700 \mathrm{~m}$ is $-129^{\circ}$ $\pm 42^{\circ}$ (95\% confidence) supporting the presence of a node in this depth interval.

\section{e. 26.1 hours}

This is the one period at which the autospectral peaks are consistently significant and coherence am- 

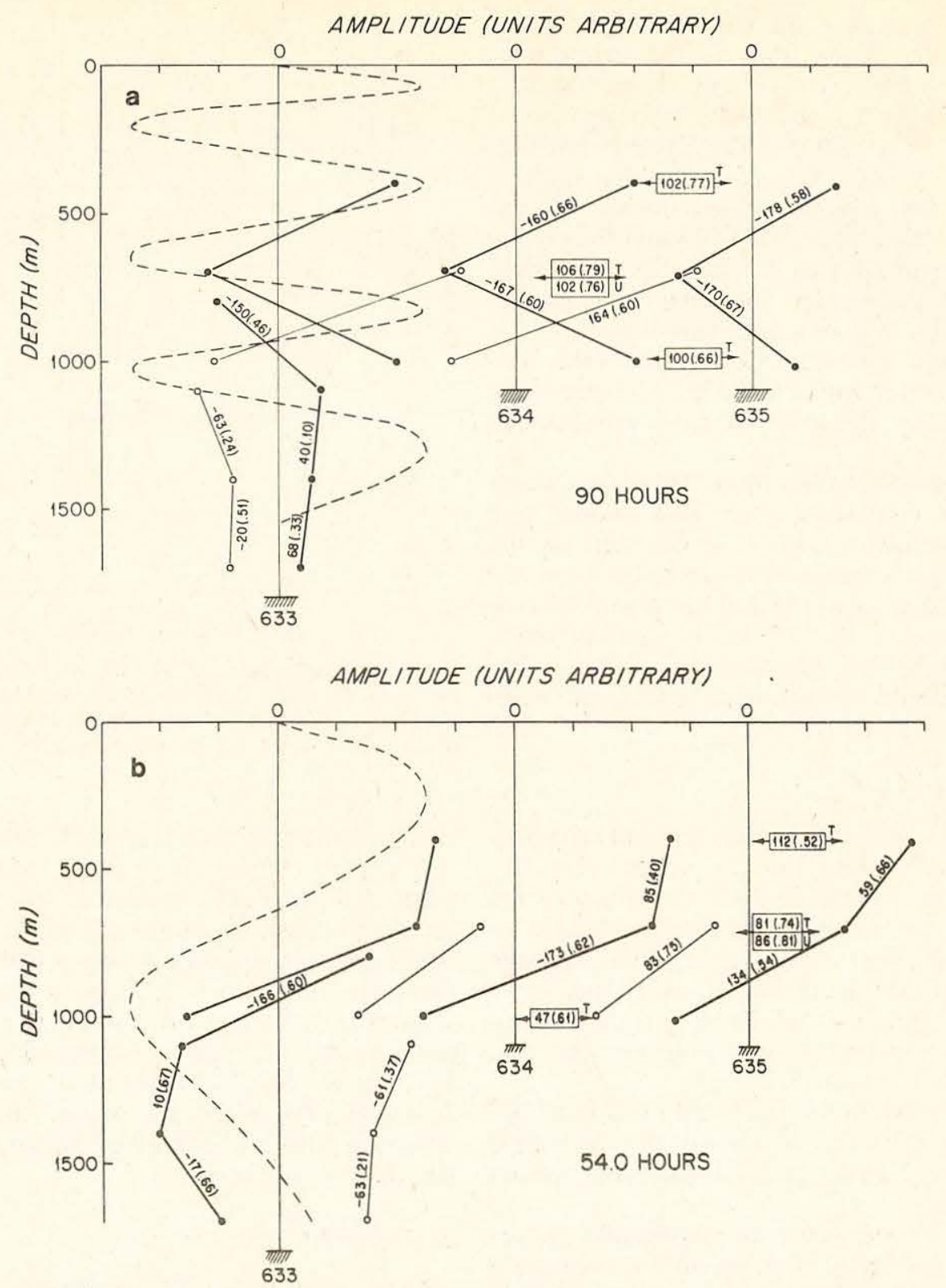

Fig. 13. Amplitudes versus depth for the four sub-inertial resonant periods at the three different near-field moorings. Temperature information from 634 has been transposed onto the top of 633 along with the normalized vertical mode computed using values of $\epsilon^{1 / 2}$ obtained from Fig. 12. All temperature amplitudes (solid dots) were normalized so that their spectra overlay in the $7-8 \mathrm{~h}$ band to remove effects of depth varying stratification. If the same normalization applies at all frequencies, as it should in the WKB approximation, temperature should be a sinusoid of varying wavelength but constant amplitude. No adjustments were made to longshore velocity (open circles). (a) $90 \mathrm{~h}$, (b) $54 \mathrm{~h}$, (c) $42.6 \mathrm{~h}$ and (d) $26.1 \mathrm{~h}$.

plitudes are large enough to indicate non-modal vertical and azimuthal structure which we shall attempt to explain.

There are a number of diurnal tidal lines in the vicinity of $26.1 \mathrm{~h}$, the most important being $Q_{1}$ $(26.87 \mathrm{~h}), O_{1}(25.8 \mathrm{~h}), P_{1}(24.07 \mathrm{~h})$ and $K_{1}(23.93 \mathrm{~h})$. In Fig. 14 we show their expected contributions superposed on more highly resolved autospectra of longshore current and temperature. The $O_{1}$ and $P_{1}$ lines are the strongest barotropic tides being approximately equal; however, the island response greatly favors the longer period $Q_{1}, O_{1}$ range, strong evidence for a resonance in this frequency range. Further support for this conclusion will be 

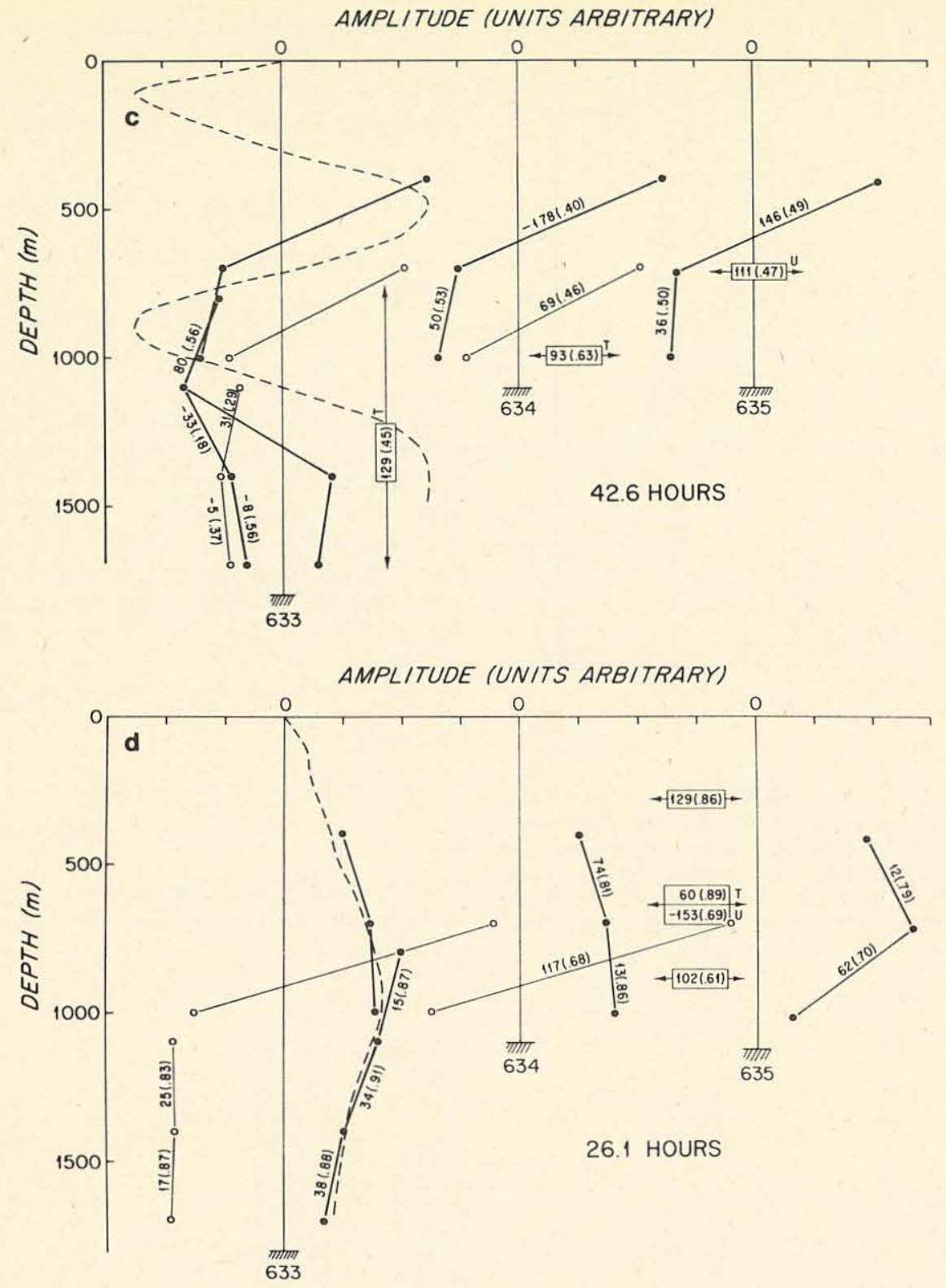

Fig. 13. (Continued)

given in Section 7 but it should also be noted that the first WKB flat-bottom mode does resonate very near this frequency.

Given the existence of a first azimuthal, first vertical mode at $26.1 \mathrm{~h}$ and a first azimuthal, second vertical mode at $54.0 \mathrm{~h}$, the dispersion curves in Fig. 11 predict a second azimuthal, second vertical mode at $\sim 28 \mathrm{~h}$, very close to the $26.1 \mathrm{~h}$ resonance point. The azimuthal phase information shown on Fig. 13d and given in Table 5 is consistent with motions which are dominated by mode 2 at 400 and $1000 \mathrm{~m}$ but by mode 1 at $700 \mathrm{~m}$. One explanation for the nonmodal vertical phase is that there are two correlated vertical modes-uncorrelated modes would give the usual $0^{\circ}$ or $\pm 180^{\circ}$ phase differences.

With the temperature amplitudes and phases in Fig. 13d projected as vectors, $\mathbf{T}\left(z_{j}\right)$, on a complex phase plane we consider the modal decomposition at each mooring

$$
\mathbf{T}\left(z_{j}\right)=\mathbf{a}_{1} T_{1}\left(z_{j}\right)+\mathbf{a}_{2} T_{2}\left(z_{j}\right)+\boldsymbol{\epsilon}_{j} .
$$

Here $a_{1}$ and $a_{2}$ are the vector amplitudes of the contributions of the first and second vertical modes whose amplitude versus depth distribution $T_{i}\left(z_{j}\right)$ we can estimate from the WKB approximation to the first mode and the observed structure at $54.0 \mathrm{~h}$ for 


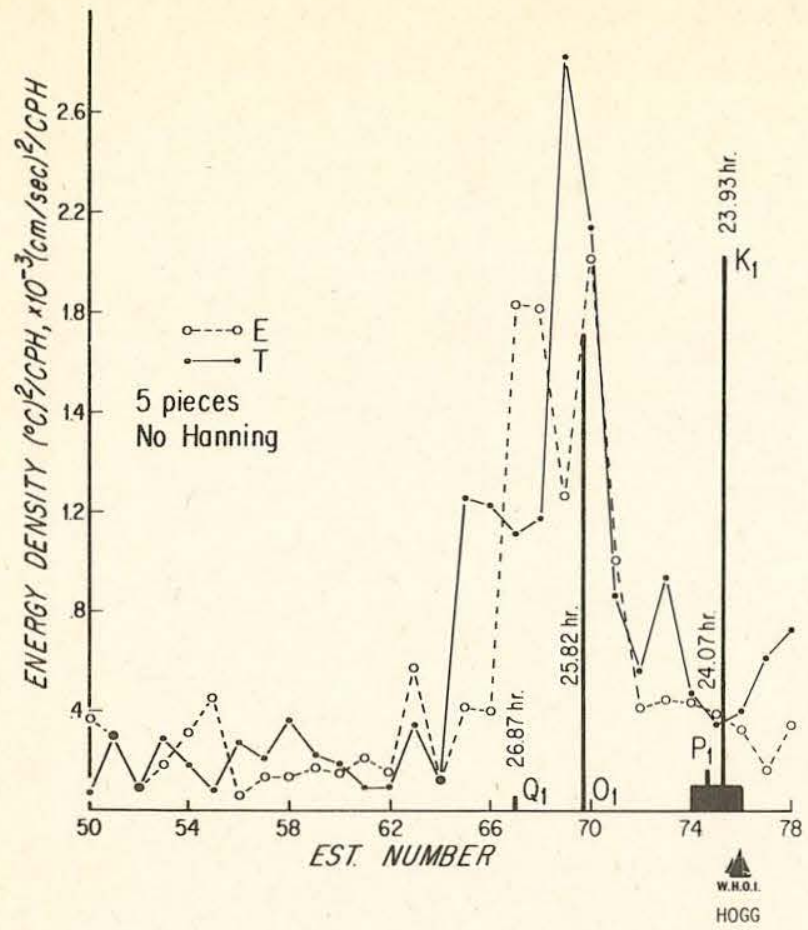

FIG. 14. High-resolution spectra of temperature $(T)$ and longshore velocity $(E)$ on mooring 634 at $700 \mathrm{~m}$ depth. Also shown are the relative energy densities of the four most important diurnal tidal constituents. The actual energy density of the barotropic tidal velocity in the $P_{1}-K_{1}$ band is shown by the solid bar and was estimated from measured amplitudes and the long wave equation. the second, each normalized by their amplitude at $400 \mathrm{~m} . \epsilon_{j}$ is the error. Fitting each component of $T_{i}\left(z_{j}\right)$ at each mooring in a least-squares sense according to (17) gives the results

at 635 :

at 634 :

$$
\begin{aligned}
& \mathbf{a}_{1}=(0.60,-0.29)=0.67 e^{-i 2.6^{\circ}} \\
& \mathbf{a}_{2}=(1.64,0.14)=1.65 e^{i 4.9^{\circ}}
\end{aligned}
$$

$$
\begin{aligned}
& \mathbf{a}_{1}=(0.50,0.59)=0.77 e^{i 50^{\circ}} \\
& \mathbf{a}_{2}=(-0.17,0.20)=0.74 e^{i 164^{\circ}} .
\end{aligned}
$$

In the circular island approximation the modal amplitudes should be constant - a fact supported by the results for the first mode but less well for the second. Furthermore, $\mathbf{a}_{1} \sim \exp \left[-\left(\theta+\phi_{1}\right) i\right]$ and $\mathbf{a}_{2} \sim \exp \left[\left(2 \theta+\phi_{2}\right) i\right]$, where $\theta$ is the geometrical mooring position and $\phi_{i}$ the relative phases. Therefore, the phase differences between moorings for mode 1 are

$\left(-\theta_{634}+\phi_{1}\right)-\left(-\theta_{635}+\phi_{1}\right)=\theta_{635}-\theta_{634}=+76^{\circ}$, and mode 2 ,

$$
\begin{aligned}
\left(-2 \theta_{634}+\phi_{2}\right)-\left(-2 \theta_{635}\right. & \left.+\phi_{2}\right) \\
& =2\left(\theta_{635}-\theta_{634}\right)=+160^{\circ} .
\end{aligned}
$$

These results are internally self consistent and reasonably close to the $50^{\circ}$ expected angular separation.

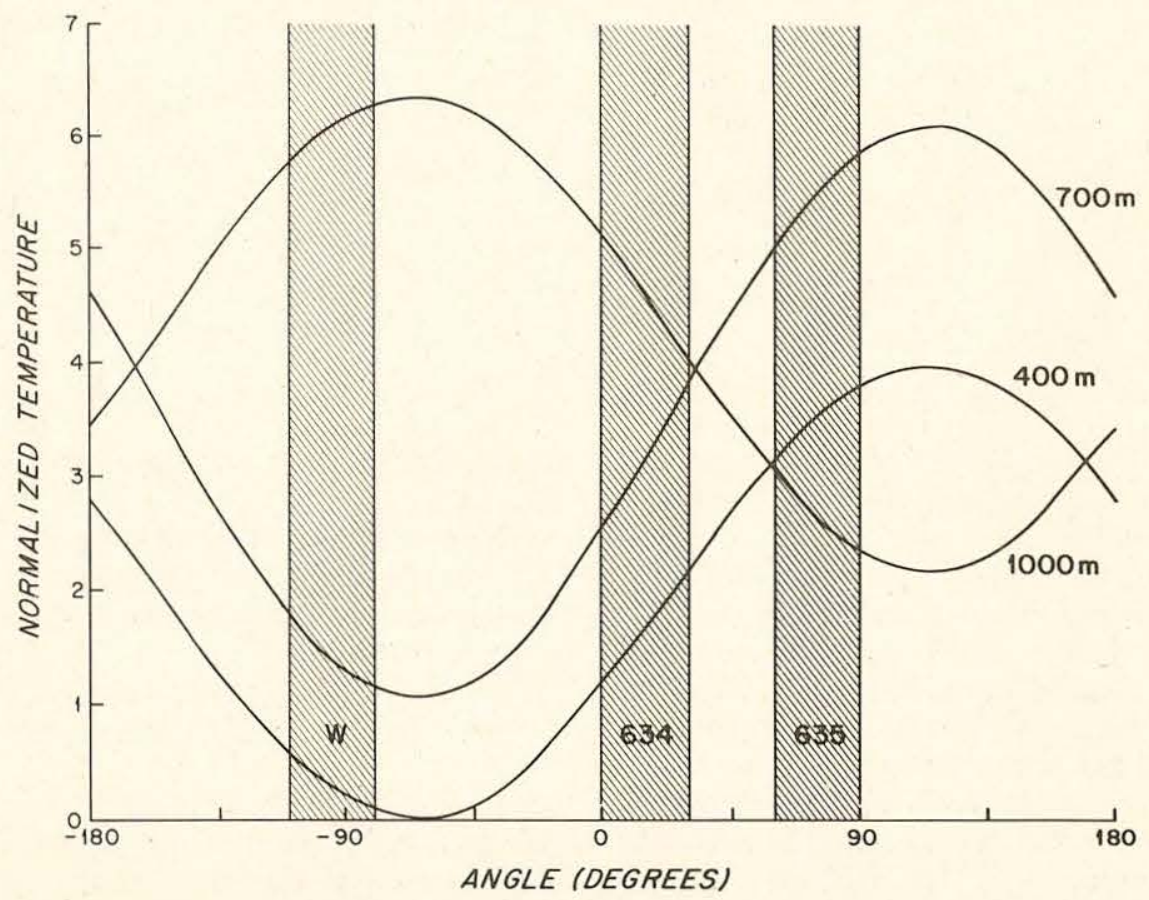

Fig. 15. Azimuthal dependence of the normalized sum of the correlated first and second modes at $26.1 \mathrm{~h}$. W indicates the location of Wunsch's (1972) work. 


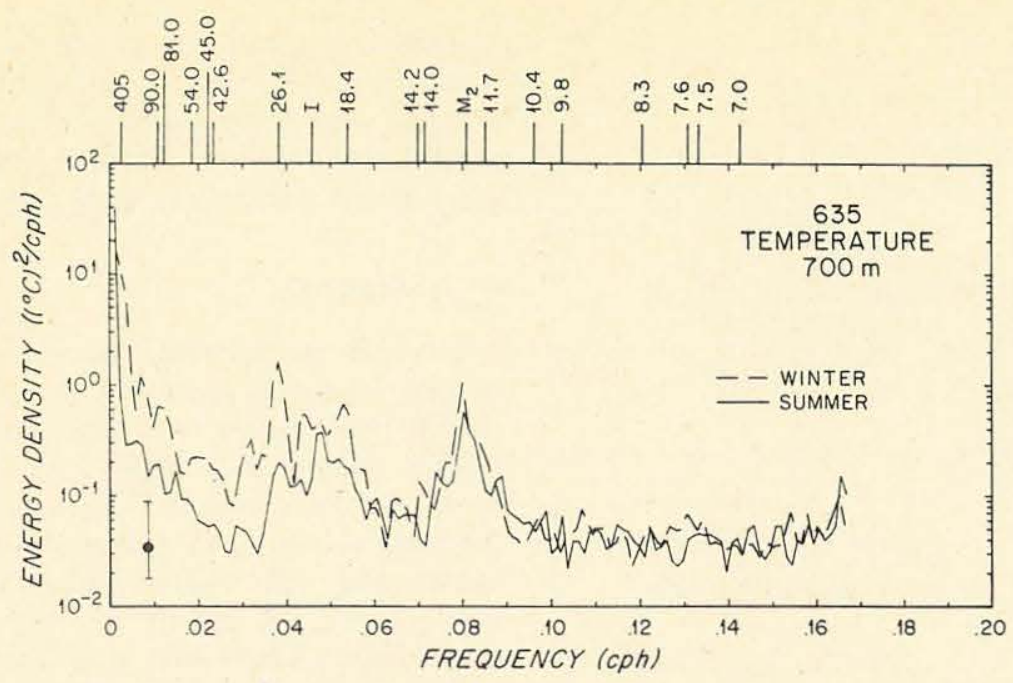

FIG. 16. A comparison between summer and winter of spectra of temperature on 635 at $700 \mathrm{~m}$.

FILTERED
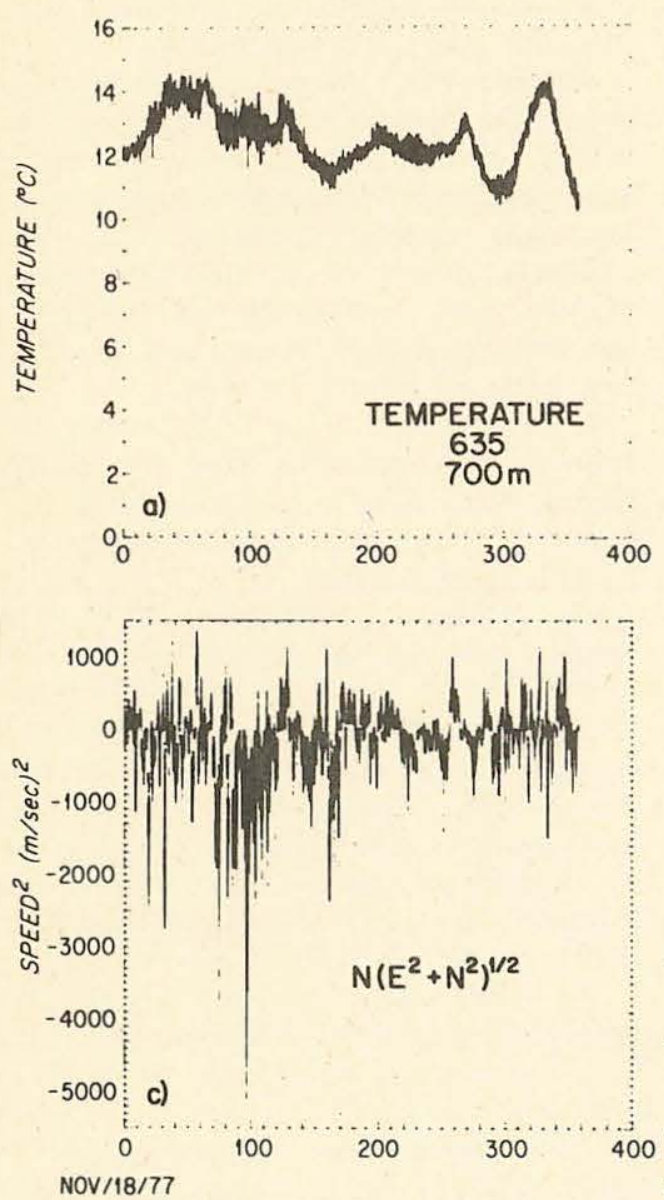

TIME (DAYS)
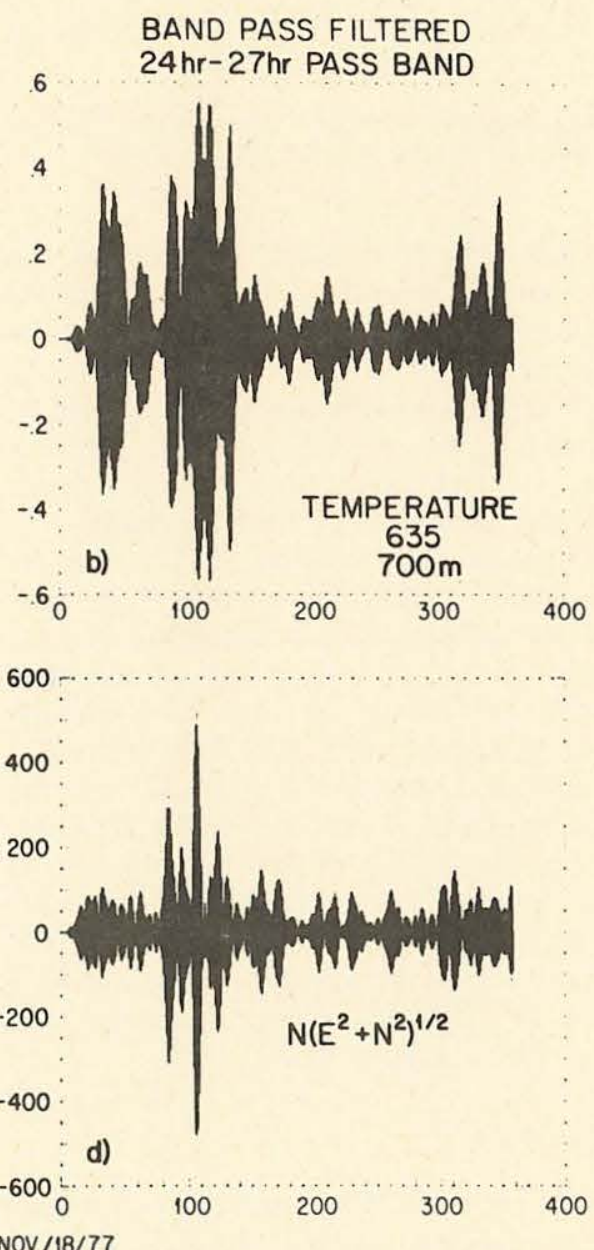

FIG. 17. Plots of (a) temperature at $700 \mathrm{~m}$ on 635 , and (c) a quantity proportional to the north wind stress. (b) and (d) are band-pass filtered versions of (a) and (c), respectively. 


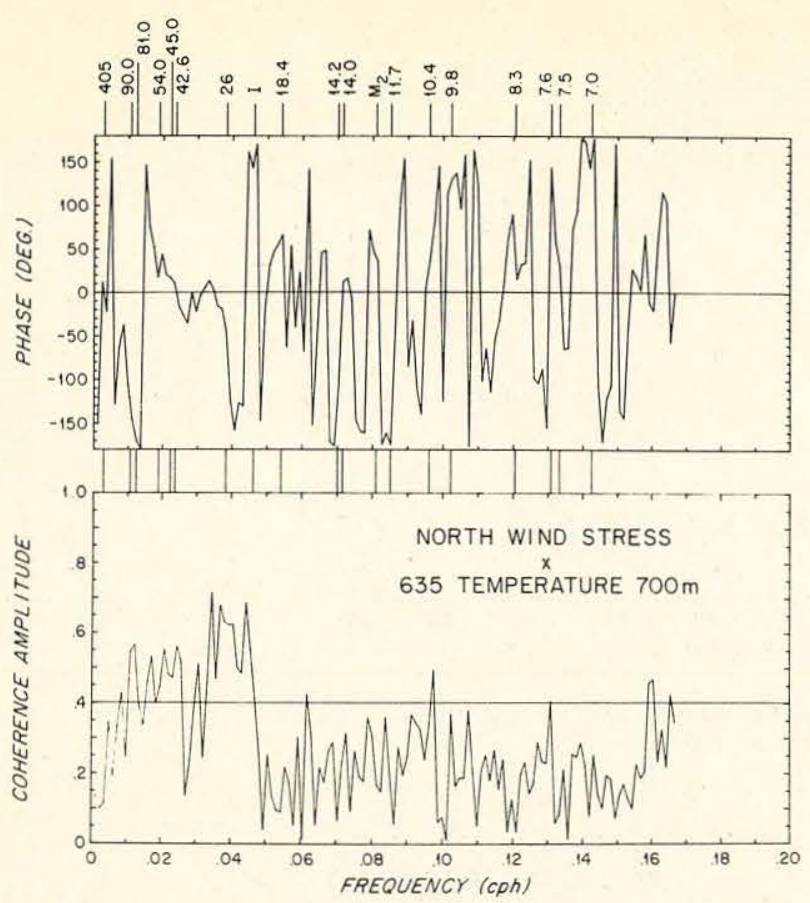

FIG. 18. Coherence amplitude and phase between north surface wind stress and temperature at $700 \mathrm{~m}$ depth.

It is of interest to note that the $26.1 \mathrm{~h}$ peak has not been previously identified in near-Bermuda spectra, although it is very prominent in ours. The published spectra are those of Wunsch (1972) at $550 \mathrm{~m}$ depth computed from temperature observations of Haurwitz et al. (1959) at the location shown in Fig. 1 off the southwest of the island. Here there is no evidence of such a peak.

The coupled mode interpretation of (17) consists of two waves which constructively interfere over half the island circumference and destructively over the other half. Plotted as a function of azimuth we have the result shown in Fig. 15 with the locations of moorings 634 and 635 and Wunsch's observations indicated. Above the depth of the node for the second vertical mode the two modes destructively interfere in the region of Wunsch's work so as to produce little signal. Returning to the farfield phases given in Table 4 we also note that they are consistent with this interpretation, mode 2 being indicated at $1000 \mathrm{~m}$ between moorings 555 and 553 along the southern coast.

\section{f. Superinertial modes}

At frequencies greater than inertial wave motions cannot be trapped to the island (LonguetHiggins, 1967, 1969) although their leakage of energy can be exceedingly small (Longuet-Higgins, 1967). At none of the superinertial frequencies identified in the previous section is the vertical or azimuthal phase information complete enough to allow presen- tations comparable to those for these in the subinertial band. Except to conclude that high-frequency trapped waves appear to exist, with the apparent modal structure tabulated in Tables 4, 5, 7 and 8, no further analysis is presented.

\section{Excitation}

Several mechanisms have been suggested for forcing island trapped waves and maintaining them against dissipation and radiation. Longuet-Higgins (1967) shows that they can be forced by the scattering of incident waves or pulses. However, for internal motions there are no free waves between the very slow baroclinic Rossby waves with periods of a year or more and the internal wave band. There are long barotropic waves and nonlinear, isolated events (e.g., eddies, Gulf Stream Rings) which could interact with the island in such a way as to convert part of their energy into trapped waves. In the internal wave range there is abundant deep sea internal wave energy, more or less isotropically distributed, available for scattering into the leaky trapped modes.

Wunsch (1972) discovered that the spectrum computed over the winter months contained more energy in the subinertial band than one computed over summer months although energy in a peak at 18 $19 \mathrm{~h}$ was roughly constant. He suggested that weather, known to be more energetic in winter months, was forcing the low-frequency motions but that the higher frequencies resulted from the scattering of internal waves.

A final possibility, at least insofar as the $26.1 \mathrm{~h}$ peak is concerned, is that the ocean is being forced at or near a resonant point by the barotropic tide, the diurnal constituents at 25.82 and $26.87 \mathrm{~h}$ in particular.

Fig. 16 shows spectra computed over the first half (winter) and last half (summer) of the temperature time series at $700 \mathrm{~m}$ on 634 . We have a similar result to Wunsch's for the subinertial band. Energy is higher by an order of magnitude in the winter months. No significant differences are seen in the superinertial band but, on the other hand, we see no significant peaks here either, contrary to Wunsch's results. Tidal forcing should be roughly constant and, therefore, can be ruled out.

We have obtained through the National Weather Service three hourly time series of sea level pressure and surface winds for Bermuda coincident with our moored records. In Fig. 17 we show the full time series of the temperature on 635 at $700 \mathrm{~m}$ depth and the north component of wind stress. Also shown are both series band-pass filtered so as to pass energy between 24 and $27 \mathrm{~h}$-the most prominent peak on our records. There is a clear correlation between periods of strong wave motion at $700 \mathrm{~m}$ depth and strong surface wind stress both 
reaching their largest amplitudes during late fall and winter of 1977 and again in November of 1978.

Finally, shown in Fig. 18 are the coherence amplitude and phase between the north component of wind stress and temperature at $700 \mathrm{~m}$ depth. There is significantly nonzero coherence between the two variables in a broad band around $26.1 \mathrm{~h}$, a band between 40 and $60 \mathrm{~h}$ and again from $75 \mathrm{~h}$ to $90 \mathrm{~h}$-the four subinertial trapped wave bands. Inspection of the phase change with frequency shows a $180^{\circ}$ change around $90 \mathrm{~h}$, a further $180^{\circ}$ change just below $54 \mathrm{~h}$ and finally a $180^{\circ}$ jump centered on $26.1 \mathrm{~h}-\mathrm{a}$ convincing demonstration of resonant dynamical response of the ocean to atmospheric forcing.

If the 54.0 and $42.6 \mathrm{~h}$ periods are, indeed, separate modes we might have expected there to be an additional $180^{\circ}$ phase change. However, the modes change in both azimuthal and vertical mode number and, given a response bandwidth comparable to the separation between the two frequencies it is not clear that there needs to be a $180^{\circ}$ phase change.

From the high-resolution spectra of Fig. 14 we can compute an approximate $Q$ for the motions. The ratio of center frequency to peak half-width is at least 20 suggesting that viscous decay is relatively unimportant.

\section{Conclusions}

Evidence from two moored arrays near Bermuda has been presented which conclusively shows the existence of baroclinic waves trapped near the island. A reasonable fit to the theoretical dispersion relation is obtained if one chooses a bottom depth which is some average of the actual variable depth over the offshore trapping scale of the waves. Azimuthal modes 1 and 2 and vertical modes 1-4 are observed. A strong spectral peak centered at $26.1 \mathrm{~h}$ is the fundamental and does not appear related to tidal energy near this frequency. The structure at $26.1 \mathrm{~h}$ is actually best explained by both first azimuthal, first vertical and second azimuthal, second vertical modes which are correlated. Their interference pattern also explains the absence of a spectral peak in previous observations made on the opposite side of the island.

Superinertial trapped modes are also indicated although there are no significant autospectral peaks above the inertial frequency, except for the tides. Mode numbers are generally higher, both in the azimuth and vertical and in the far and near fields. The signal to noise ratio is low, however, and we cannot describe these motions well except to have reasonable confidence that they exist.

The subinertial motions are almost certainly forced by the local surface winds. There exists a good correlation between periods of intense winds and energetic temperature fluctuations at $700 \mathrm{~m}$ depth in a band centered on the fundamental mode. There also exists a significant coherence amplitude between surface wind stress and temperature at $700 \mathrm{~m}$ depth at each of the subinertial resonant periods. This is a remarkable occurrence in any event but the phase also changes through $180^{\circ}$ at three of these periods-conclusive evidence for resonant forcing.

Acknowledgments. This work owes a great debt to the WHOI Buoy Group for their expert handling of the mooring operation and the subsequent data processing. Special thanks are due the captain and crew of the U.S. Coast Guard vessel Evergreen for their assistance in recovering the far-field array and to Austin Talbot and Tony Knapp of Bermuda for the discovery and recovery of one of the moorings in the near-field array from the rocks of Bermuda. Financial support has come from the Office of Naval Research under Contracts N00014-74-C-0262, NR083-004 and N00014-76-C-0197, NR083-400. This is contribution number 4178 from the Woods Hole Oceanographic Institution.

\section{APPENDIX}

\section{Average Angular Separation}

Consider the problem of estimating a mean $m$ and standard error $s$ from two processes $x$ and $y$ each of which has the same expected mean $\left[E\left(m_{x}\right)=E\left(m_{y}\right)\right.$ $=m]$ but different standard error $\left(s_{x}=s_{y}\right)$. The extension to more than two variables is straightforward and our objective is to estimate overall averages of the angular separations between moorings from a number of individual estimates which we believe to have a common mean but come from different realizations with different signal-to-noise ratios. We assume that the processes result from normal distribution.

The normalized variables

$$
X_{i}=\frac{x_{i}-m}{\sigma_{y}}, \quad Y_{i}=\frac{y_{i}-m}{\sigma_{y}},
$$

have zero expected mean and unit variance. If $i$ is a dummy index ranging between 1 and the effective number of measurements $N$ (i.e., the number of degrees of freedom), then the pooled variable

$$
\begin{aligned}
Z_{i} & =X_{i}, \quad i=1, N \\
& =Y_{i-N}, \quad i=N+1,2 N
\end{aligned}
$$

also has zero mean and unit variance. Therefore,

$$
\begin{array}{r}
0=E\left(Z_{i}\right)=\frac{1}{2 N}\left[\sum_{i=1}^{N}\left(\frac{x_{i}-\hat{m}}{\hat{\sigma}_{m}}\right)+\sum_{i=1}^{N}\left(\frac{y_{i}-\hat{m}}{\hat{\sigma}_{y}}\right)\right] \\
=\frac{1}{2}\left[\frac{\hat{m}_{x}-\hat{m}}{\hat{\sigma}_{x}}+\frac{\hat{m}_{y}-\hat{m}}{\hat{\sigma}_{y}}\right]
\end{array}
$$


and

$$
\hat{m}=\frac{\hat{\sigma}_{y} \hat{m}_{x}+\hat{\sigma}_{x} \hat{m}_{y}}{\hat{\sigma}_{x}+\hat{\sigma}_{y}} .
$$

If $x_{i}$ and $y_{i}$ are assumed independent, the variance about this mean is given by

$$
\begin{array}{r}
\hat{\sigma}^{2}=V(m)=E\left[\left(\frac{\sigma_{y} \frac{1}{N} \sum_{1}^{N} x_{i}+\sigma_{x} \frac{1}{N} \sum_{1}^{N} y_{i}}{\sigma_{x}+\sigma_{y}}\right.\right. \\
\left.\left.-\frac{\sigma_{y} m_{x}+\sigma_{x} m_{y}}{\sigma_{x}+\sigma_{y}}\right)^{2}\right]=2\left(\frac{\hat{\sigma}_{x} \hat{\sigma}_{y}}{\hat{\sigma}_{x}+\hat{\sigma}_{y}}\right)^{2} .
\end{array}
$$

The standard error will then be

$$
s=\frac{\hat{\sigma}}{\sqrt{2 N-2}}=\frac{s_{x} s_{y}}{s_{x}+s_{y}} .
$$

\section{REFERENCES}

Allen, J. S., 1975: Coastal trapped waves in a stratified ocean. J. Phys. Oceanogr., 5, 300-325.

Cutchin, D. L., and R. L. Smith, 1973: Continental shelf waves: Low-frequency variation in sea level and currents over the Oregon continental shelf. J. Phys. Oceanogr., 3, 274-279.

Fuller, J. D., and L. A. Mysak, 1977: Edge waves in the presence of an irregular coast line. J. Phys. Oceanogr., $7,846-855$.

Hannan, E. J., 1970: Multiple Time Series. Wiley, $536 \mathrm{pp}$.

Haurwitz, B., H. Stommel and W. H. Munk, 1959: On thermal unrest in the ocean. Rossby Memorial Volume, Rockefeller Institute Press, 74-94.

Hogg, N. G., T. B. Sanford and E. J. Katz, 1978: Eddies, islands land mising. J. Geophys. Res., 83, 2921-2938.

Hunt, Mary, 1977: A program for spectral analysis of time series. WHOI Tech. Memo. WHOI-2-77 (unpublished manuscript).

Huthnance, J. M., 1975: On trapped waves over a continental shelf. J. Fluid Mech., 69, 689-704.

- 1978: On coastal trapped waves: Analysis and numerical calculation by inverse iteration. J. Phys. Oceanogr. 8, 74-92.

Julian, P. R., 1975: Comments on the determination of significance levels of the coherence statistic. J. Atmos. Sci., 32, 836-837.
Koopmans, L. H., 1974: Spectral Analysis of Time Series. Academic Press, $366 \mathrm{pp}$.

Longuet-Higgins, M. S., 1967: On the trapping of wave energy round islands. J. Fluid Mech., 29, 781-821.

, 1969: On the trapping of long-period waves round islands. J. Fluid Mech., 37, 773-784.

1970: Steady currents induced by oscillations round islands. J. Fluid Mech., 42, 701-720.

- 1971: On the spectrum of sea level at Oahu. J. Geophys. Res., 76, 3517-3522.

Miyata, M., and G. W. Groves, 1968: Note on sea-level observations at two nearby stations. J. Geophys. Res., 73, 3965-3967.

Morse, P. M., and H. Feshbach, 1953: Methods of Theoretical Physics, Part I. McGraw-Hill, 997 pp.

Mysak, L. A., 1967: On the theory of continental shelf waves. J. Mar. Res., 25, 205-227.

- 1968: Edgewaves on a gently sloping continental shelf of finite width. J. Mar. Res., 26, 24-33.

Ou, Hsien Wang, 1979: On the propagation of free topographic Rossby waves near continental margins. Ph.D. thesis, MITWHOI Joint Program in Physical Oceanography, 133 pp.

Reid, R. O., 1958: Effect of Coriolis force on edge waves (1). Investigation of the normal modes. J. Mar. Res., 16, 109-144.

_, 1970: Edge-, bottom-, and Rossby waves in a rotating stratified fluid. Geophys. Fluid Dyn., 1, 273-302.

Richman, J. G., C. Wunsch and N. G. Hogg, 1977: Space and time scales of mesoscale motion in the western North Atlantic. Rev. Geophys. Space Phys., 15, 385-420.

Sanford, T. B., and N. G. Hogg, 1977: The North Atlantic fine and microstructure cruise Knorr 52 and Eastward 75-12. WHOI Tech. Rep., WHOI-77-11 (unpublished manuscript).

Schmitz, W. J., Jr., 1974: Observations of low-frequency current fluctuations on the Continental Slope and Rise near Site D. J. Mar. Res., 3, 233-251.

Suarez, A., 1971: The propagation and generation of topographic oscillations in the ocean. Ph.D. thesis, Dept. of Meteorology, MIT, $130 \mathrm{pp}$.

Summerfield, W. C., 1969: On the trapping of wave energy by bottom topography. Res. Pap. No. 30, Horace Lamb Center for Oceanographical Research, Flinders University of South Australia, $214 \mathrm{pp}$.

Wang, D-P., and C. N. K. Mooers, 1976: Coastal-trapped waves in a continuously stratified ocean. J. Phys. Oceanogr., 6, 853-863.

_- and 1977: Long coastal-trapped waves off the west coast of the United States, summer 1973. J. Phys. Oceanogr., 7, 856-864.

Wunsch, Carl, 1972: The spectrum from two years to two minutes of temperature fiuctuations in the main thermocline at Bermuda. Deep-Sea Res., 19, 577-593. 


\section{MANDATORY DISTRIBUTION LIST}

\section{FOR UNCLASSIFIED TECHNICAL REPORTS, REPRINTS, AND FINAL REPORTS PUBLISHED BY OCEANOGRAPHIC CONTRACTORS \\ OF THE OCEAN SCIENCE AND TECHNOLOGY DIVISION \\ OF THE OFFICE OF NAVAL RESEARCH}

\section{(REVISED NOVEMBER 1978)}

1 Deputy Under Secretary of Defense (Research and Advanced Technology) Military Assistant for Environmental Science Room 3D129

Washington, D.C. 20301

Office of Naval Research 800 North Quincy Street Arlington, VA 22217

3 ATTN: Code 483

1 ATTN: Code 460

2 ATTN: 102B

1 CDR J. C. Harlett, (USN) ONR Representative Woods Hole Oceanographic Inst. Woods Hole, MA 02543

Commanding officer Naval Research Laboratory Washington, D.C. 20375

6 ATTN: Library, Code 2627
12 Defense Documentation Center Cameron Station Alexandria, VA 22314 ATTN: DCA

Commander Naval Oceanographic Office NSTL Station

Bay St. Louis, MS 39522

1 ATTN: Code 8100

1 ATTN: Code 6000

1 ATTN: Code 3300

1 NODC/NOAA

Code D781

Wiscons in Avenue, N.W. Washington, D.C. 20235 


\begin{tabular}{|c|c|}
\hline REPORT DOCUMENTATION PAGE & $\begin{array}{l}\text { READ INSTRUCTIONS } \\
\text { BEFORE COMPLETING FORM }\end{array}$ \\
\hline $\begin{array}{l}\text { 1. REPORT NUMBER } \\
\text { WHOI }-81-33\end{array}$ & 3. RECIPIENT'S CATALOG NUMBER \\
\hline \multirow{2}{*}{$\begin{array}{l}\text { 4. TITLE (and Subtitio) } \\
\text { OBSERVATIONS OF INTERNAL KELVIN WAVES TRAPPED } \\
\text { ROUND BERMUDA }\end{array}$} & $\begin{array}{l}\text { 5. TYPE OF REPORT \& PERIOD COVERED } \\
\text { Technical }\end{array}$ \\
\hline & $\begin{array}{l}\text { 6. PERFORMING ORG. REPORT NUMBER } \\
\text { WHOT Cont. \#4178 }\end{array}$ \\
\hline $\begin{array}{l}\text { 7. AUTHOR(a) } \\
\text { Nelson G. Hogg }\end{array}$ & $\begin{array}{l}\text { 8. CONTRACT OR GRANT NUMBER(a) } \\
\text { * N00014-74-C-0262; } \\
\text { N00014-76-C-0197; }\end{array}$ \\
\hline $\begin{array}{l}\text { 9. PERFORMING ORGANIZATION NAME AND ADDRESS } \\
\text { Woods Hole Oceanographic Institution } \\
\text { Woods Hole, Massachusetts } 02543\end{array}$ & $\begin{array}{l}\text { 10. PROGRAM ELEMENT, PROJECT, TASK } \\
\text { *NREA A WORK UNIT NUMBERS } \\
\text { NR } 083-004 \\
\text { NR } 083-400\end{array}$ \\
\hline $\begin{array}{l}\text { 11. CONTROLLING OFFICE NAME AND ADDRESS } \\
\text { NORDA- National Space Technology Laboratory } \\
\text { Bay St. Louis, MS } 39529\end{array}$ & $\begin{array}{l}\text { 12. REPORT DATE } \\
\text { April } 1981 \\
\text { 13. NUMBER OF PAGES }\end{array}$ \\
\hline \multirow{2}{*}{ 14. MONITORING AGENCY NAME Q ADDRESS(It different from Controlling Office) } & $\begin{array}{l}\text { 15. SECURITY CLASS. (of thio roport) } \\
\text { Unclassified }\end{array}$ \\
\hline & $\begin{array}{l}\text { 15a. DECLASSIFICATION/DOWNGRADING } \\
\text { SCHEDULE }\end{array}$ \\
\hline
\end{tabular}

Approved for public release; distribution unlimited.

17. DISTRIBUTION STATEMENT (of the abotract ontered in Block 20, if dilforent from Report)

18. SUPPLEMENTARY NOTES

Reprinted from: Journal of Physical Oceanography 10(9): 1353-1376

(September 1980).

19. KEY WORDS (Continue on peverse alde If noceseary and identily by block number)

1. Island trapped waves

2. Internal Kelvin waves

3. Coastal trapped waves

20. ABSTRACT (Continue on roverse oldo if necoseary and identify by block number)

See back 
Observations of the vertical and horizontal structure of motions near Bermuda have been made with two long-term moored arrays, one relatively far from and the other close to the island. Although not coincident in time, both arrays see horizontally coherent motions at 11 frequency bands ranging in period from 405 to $9.8 \mathrm{~h}$. Only a peak at $26.1 \mathrm{~h}$. appears to be significant in the autospectra and, on several grounds, this is identified with the fundamental island-trapped mode (vertically and azimuthally).

Additional resonant subinertial periods are at roughly 45, 54 and $90 \mathrm{~h}$ and these are vertical modes 2, 3 or 4 and azimuthal modes 1 or propagating clockwise. The superinertial modes have less internal consistency but appear to have higher order vertical and azimuthal structures and both senses of azimuthal phases propagation.

The subinertial vertical structure is modal and can be rationalized with baroclinic wave dynamics on a sloping bottom by defining an effective bottom depth as some reasonable average over the offshore decay scale.

The subinertial motions are coherent with the surface wind stress and the phase between this forcing and the response changes by $180^{\circ}$ across the trapped wave frequency bands consistent with a resonant system. The $Q$ of the $26.1 \mathrm{~h}$ peak is at least implying that dissipation has only a slight influence on the dynamics. 


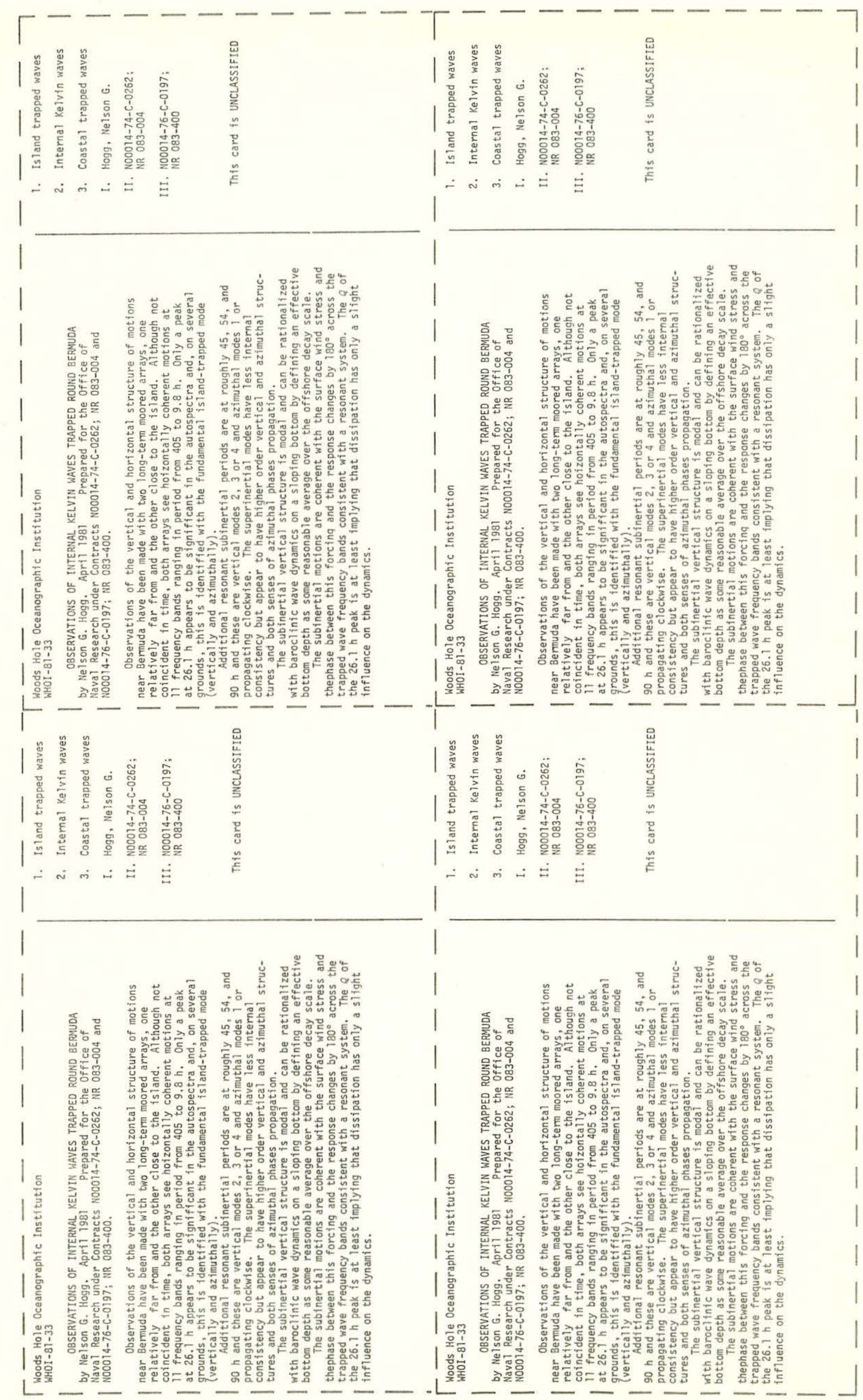

